\title{
FORMULATION AND DEVELOPMENT OF FIXED-DOSE COMBINATION OF BI-LAYER TABLETS OF EFAVIRENZ, LAMIVUDINE AND TENOFOVIR DISOPROXIL FUMARATE TABLETS 600 MG/300 MG/300 MG
}

\author{
JONNA SANKARAIAH ${ }^{1 *}$, NEERAJ SHARMA², MOHD. JAVED NAIM ${ }^{3 *}$ \\ ${ }^{*}$ Department of Pharmaceutics, Bhagwant University, Ajmer, Rajasthan, India, 2,3Faculty of Pharmacy, Bhagwant University, Ajmer, \\ Rajasthan, India \\ Email: javednaim88@rediffmail.com
}

Received: 28 Jul 2021, Revised and Accepted: 06 Dec 2021

\begin{abstract}
Objective: This study is to formulate bi-layer tablet as a multidrug regimen against each reference listed drugs of Brand SUSTIVA® (efavirenz tablets $600 \mathrm{mg}$ ), EPIVER®(lamivudine tablets $300 \mathrm{mg}$ ), and VIREAD®(tenofovir disoproxil tablets $300 \mathrm{mg}$ ) to treat human immunodeficiency virus (HIV) infections. Which provides highly active antiretroviral therapy to provide effective treatment.

Methods: Bilayer formulation was developed with each blend of layer-I (efavirenz) and layer-II (lamivudine and tenofovir disoproxil fumarate) through wet granulation process and roller compaction process, respectively. Further, both layers were compressed by using bi-layer compression followed by film coating. Layer-I and II formulations were developed by using various concentrations of diluents, surfactants, and disintegrants to improve the solubility of efavirenz and improve the flowability and uniformity of layer-II. Finally, the optimum formulation was developed to compare the in vitro dissolution with each branded formulation.

Results: Drug-excipients interaction results revealed that the mixtures of three drug substances in $50{ }^{\circ} \mathrm{C} / 75 \%$ relative humidity (RH) resulted in an increase in tenofovir IMP-E and the highest unknown impurity was significantly increased and additionally decreased tenofovir assay in the presence of efavirenz. Sodium lauryl sulfate is very critical and it acts as a wetting agent and increases the solubility of efavirenz, and directly influences the dissolution of a drug product. Microcrystalline and croscarmellose sodium have a chance to affect the dissolution and friability of tenofovir. Powdered cellulose was acting as a diluent and flow property of the lamivudine part and it also affects the uniformity and dissolution. So, these ranges were optimized. X-ray diffraction (XRD) indicates there are no polymorphic changes for the optimized formulation and there is no interaction between the three active substances, and finally, in vitro dissolution results for the optimized formulation against the reference drugs.
\end{abstract}

Conclusion: Optimum formulation yielded consistent drug release against each branded drug to treat human immunodeficiency virus (HIV1) infections. This formulation is robust and easily scale up for the next stage.

Keywords: Fixed-dose formulation, Human immunodeficiency virus (HIV1) infection, Bilayer compression, Efavirenz, Lamivudine, and tenofovir

(C) 2022 The Authors. Published by Innovare Academic Sciences Pvt Ltd. This is an open-access article under the CC BY license (https://creativecommons.org/licenses/by/4.0/) DOI: https://dx.doi.org/10.22159/ijap.2022v14i1.42764. Journal homepage: https://innovareacademics.in/journals/index.php/ijap

\section{INTRODUCTION}

A combination drug or a fixed-dose combination (FDC) is a medicine that includes two or moreactive ingredients combined in a single dosage form [1]. Terms like "combination drug" or "combination drug product" can be common shorthand for a fixeddose combination (FDC) product. Fixed-dose formulations can be administered as a multi-drug regimen to treat various diseases by an effect on different modes of action. From a patient perspective, they offer convenience, reduced dosing unit burden, and cost savings. From a clinical perspective, the aging population in developed countries will need multiple medications to treat age-related diseases and co-morbidities. However, the recommended fixed-dose combination (FDC) drugs such as efavirenz, lamivudine, and tenofovir disoproxil fumarate have novel approaches of multiple dosage regimens to treat human immunodeficiency virus (HIV-1) infection through nucleotide reverse transcriptase inhibitors, nonnucleoside reverse-transcriptase inhibitors.

Three active pharmaceutical ingredients (APIs) in the formulation have chances to be incompatible and may impact the related substances of the finished product. So, bilayer tablets were recommended for formulation development [2].

Human immunodeficiency virus (HIV) is a retrovirus that causes irreversible destruction of the immune system, leading to the occurrence of opportunistic infections and malignancies. The human immunodeficiency virus is found in two major forms, which are human immunodeficiency virus (HIV-1 and HIV-2). Human immunodeficiency virus (HIV-1) is the most pathogenic strain of the virus worldwide. The human immunodeficiency virus (HIV-2) is the most common in west Africa. The human immunodeficiency virus (HIV) attacks the body's immune system, especially the cluster of differentiation 4 (CD4cells) ( $\mathrm{T}$ cells), which helps the immune system fight infections. If left untreated, human immunodeficiency virus (HIV) reduces the number of clusters of differentiation 4 (CD4cells) (T cells) in the body, making the person more likely to get infections or infection-related symptom cancers $[3,4]$.

Mono-therapy is no longer recommended because incomplete viral suppression can encourage the development of resistance. Similarly, the magnitude and durability of viral suppression were lower with dual antiretroviral combinations compared with combinations containing three or more agents. For example, generally, two nucleoside reverse transcriptase inhibitors (NRTIs) are combined with an antiretroviral from PI or non-nucleoside reverse transcriptase inhibitors (NNRTI) class. Similarly, mono-therapy with PI or non-nucleoside reverse transcriptase inhibitors (NNRTI) is also not advisable to prevent the emergence of resistance and subsequent drug failure. The current strategy for the treatment of human immunodeficiency virus (HIV) infection is called highly active antiretroviral therapy (HAART) and is based on cocktails of drugs that are currently approved by the food and drug administration. These drugs include compounds that target the viral entry step and the enzymes reverse transcriptase or protease. The introduction of highly active antiretroviral therapy (HAART) has dramatically changed the landscape of human immunodeficiency virus (HIV) disease. Death from acquired immune deficiency syndrome (AIDS)-related diseases have been reduced significantly since highly active antiretroviral therapy (HAART) came into use. Nevertheless, it is not clear how long clinical benefit will last, 
considering the emergence of multiple drug-resistant viral strains. The addition of new anti-human immunodeficiency virus (HIV) drugs targeting other steps of the viral replication cycle may increase the potency of inhibition and delay resistance development. However, a multidrug regimen is commonly called highly active antiretroviral therapy to provide effective treatment $[5,6]$.

\section{MATERIALS AND METHODS}

\section{Materials}

Efavirenz, lamivudine, and tenofovir disoproxil fumarate were procured from laurus labs and a gift sample from desano. Microcrystalline cellulose, lactose monohydrate, hydroxypropyl cellulose, lactose monohydrate and powdered cellulose croscarmellose sodium, sodium lauryl sulfate, magnesium stearate, colloidal silicon dioxide, and opadry white were commercially procured and used for this study.

\section{Preformulation study}

Preformulation study was executed to understand the physical properties of drug substances and excipients that may impact on the formulation and process design and performance. Which provides knowledge for scientific foundation guidance and conserve resources in the drug development and evaluation process, enhance drug product quality $[7,8]$.

\section{Evaluation of physical parameters for active substances}

Physical parameters such as bulk density $(\mathrm{g} / \mathrm{ml})$, tapped density $(\mathrm{g} / \mathrm{ml})$, compressibility index, and hausner's ratio were verified to understand the flow property of active substances before initiation of the formulation development of fixed-dose formulation.

\section{Evaluation of particle size distribution (PSD) data for active substances}

The particle size of each tenofovir disoproxil fumarate (TDF) and lamivudine (LMV) active pharmaceutical ingredient (API) was determined by using CILAS particle size analyzer at $2000 \mathrm{mbar}$ dispensing pressure and efavirenz active pharmaceutical ingredient (API) was determined by using CILAS particle size analyzer at $500 \mathrm{~m}$ bar dispensing pressure.

\section{Solubility studies}

Solubility studies were carried out for all the active substances through the high-performance liquid chromatography (HPLC) method for the selection of the dissolution method.

\section{$\mathrm{X}$-ray diffraction (XRD) studies}

The active substances and their formulation were subjected to X-ray diffraction (XRD) studies to determine the crystalline structure of the formulation.

\section{Dissolution method development}

Both tenofovir disoproxil fumarate (TDF), lamivudine (LMV) have been classified as biopharmaceutics classification system (BCS) Class III compounds displaying high aqueous solubility. The target is an immediate release fixed-dose combination tablet and Tmax of each single entity reference listed drug (RLD) product is around 1 hour, so the dissolution of a target drug product is expected in the stomach and absorption in the upper small intestine is expected, hence suggesting the use of dissolution medium with low $\mathrm{pH}$. Tenofovir disoproxil fumarate (TDF) is soluble in $0.1 \mathrm{~N}$ hydrochloric acid $(\mathrm{HCl})$ (gastric media), sparingly soluble in $\mathrm{pH} 4.5$ acetate buffer and in $\mathrm{pH} 6.8$ phosphate buffer. Lamivudine is freely soluble in all three media.

Development began with the dissolution methods recommended in the dissolution methods database by FDA for the single entity reference listed drug (RLD) products: $900 \mathrm{ml}$ of $0.1 \mathrm{~N}$ hydrochloric acid using United States pharmacopoeia (USP) apparatus 2 at 50 rpm and temperature $37.0 \pm 0.5^{\circ} \mathrm{C}$. The results revealed that the drug release of tenofovir disoproxil fumarate (TDF), lamivudine (LMV) was not sensitive to $\mathrm{pH}$ (similar to $0.1 \mathrm{~N}$ hydrochloric acid, $\mathrm{pH} 4.5$ acetate buffer, and pH 6.8 phosphate buffers). Since the target is an immediate release product and by considering Tmax, dissolution in the stomach and absorption in the upper small intestine is expected, hence suggesting using $0.1 \mathrm{~N}$ hydrochloric acid medium $[9,10]$. Efavirenz (EFV) is known to be a biopharmaceutics classification system (BCS) Class II/IV compound displaying low aqueous solubility.

Efavirenz (EFV) is practically insoluble in $0.1 \mathrm{~N}$ hydrochloric acid, pH 4.5 acetate buffer, $\mathrm{pH} 6.8$ phosphate buffer, and purified water. Hence, efavirenz (EFV) exhibits pH-independent solubility at $37^{\circ} \mathrm{C}$. And it is very slightly soluble in purified water with $0.5 \%$ sodium lauryl sulfate (SLS), slightly soluble in purified water with $1 \%$ sodium lauryl sulfate (SLS), and purified water with $2 \%$ sodium lauryl sulfate (SLS) [11].

\section{Drug-excipient compatibility study}

Based on the literature and prior knowledge, the excipients were used for the drug-excipient compatibility study. The excipient compatibility studies were performed in two steps. The purpose of the 1st excipient compatibility study was to confirm the reaction among the drug substances and the reaction between the drug substances and sodium lauryl sulfate. The 2nd excipient compatibility study was performed to confirm the reaction between each drug substance and the excipient.

\section{First excipient compatibility study}

The samples were prepared by mixing the drug substance and the excipients in the respective ratio. And then, the resulting samples were stored in climatic chambers at $50 \pm 2{ }^{\circ} \mathrm{C} / 75 \pm 5 \%$ relative humidity (RH) conditions in both open and closed conditions in a labeled glass vial. The compatibility test period was performed for 2 $\mathrm{w}$, because the temperature condition was severe than that of the normal compatibility test condition.

\section{Second excipient compatibility study}

The samples were prepared by mixing the drug substance and the excipients in the respective ratios. And then, the resulting samples were stored in climatic chambers at $40 \pm 2{ }^{\circ} \mathrm{C} / 75 \pm 5 \%$ relative humidity $(\mathrm{RH})$ in open condition and $50 \pm 2{ }^{\circ} \mathrm{C} / 65 \pm 5 \%$ relative humidity (RH) in closed conditions in a labeled glass vial.

The physical observation data generated at $1 \mathrm{st}, 2^{\text {nd }}$, and $4^{\text {th }}$-week samples at closed condition $\left(50{ }^{\circ} \mathrm{C}, 65 \%\right.$ relative humidity $\left.(\mathrm{RH})\right)$ and open condition $\left(40{ }^{\circ} \mathrm{C}, 75 \%\right.$ relative humidity $(\mathrm{RH})$ ), found no significant change is observed, except tenofovir disoproxil fumarate (TDF)+lamivudine (LMV)+efavirenz (EFV) API blend at open condition $\left(50{ }^{\circ} \mathrm{C}, 65 \%\right.$ relative humidity $\left.(\mathrm{RH})\right)$. The chemical stability data generated at $1 \mathrm{st}, 2^{\text {nd }}$, and $4^{\text {th }}$-week samples at open conditions $\left(40{ }^{\circ} \mathrm{C} / 75 \%\right.$ relative humidity $\left.(\mathrm{RH})\right)$, no significant increase in impurities were observed except microcrystalline cellulose and colloidal silicon dioxide blend samples with tenofovir disoproxil fumarate (TDF), respectively. The chemical stability data generated at $1 \mathrm{st}, 2^{\text {nd }}$, and 4 th-week samples at closed conditions (50 ${ }^{\circ} \mathrm{C} / 65 \%$ relative humidity (RH)), no significant increase in impurities were observed except magnesium stearate blended samples with tenofovir disoproxil fumarate (TDF). As there was significant degradation observed with tenofovir disoproxil fumarate (TDF)+magnesium stearate sample under heat condition, the contact with tenofovir disoproxil fumarate (TDF) is limited by only using a small quantity in intragranular and the degradation tendency will be monitored and assured during stability study. Chromatographic results found, no significant change was observed. The physical observation data generated of $1 \mathrm{st}, 2^{\text {nd }}$-week samples at $50{ }^{\circ} \mathrm{C} / 75 \%$ relative humidity (RH) (Open and Closed conditions), a significant change was not observed except to tenofovir disoproxil fumarate (TDF)+lamivudine (LMV)+efavirenz (EFV) sample. The tenofovir disoproxil fumarate (TDF)+lamivudine (LMV)+efavirenz (EFV) sample of open condition turned brown to off-brown lumps at 1 week and 2weeks. Therefore, it is considered a bilayer tablet manufacturing process. When compared tenofovir disoproxil fumarate (TDF)+lamivudine (LMV)+efavirenz (EFV) with tenofovir disoproxil fumarate (TDF)+lamivudine (LMV), tenofovir IMP-E and highest unknown impurity are significantly increased at both 1 week and 2 weeks open condition and also observed a significant decrease 
in the assay. Therefore, the observed tenofovir disoproxil fumarate (TDF) degradation was due to lamivudine (LMV), in the presence of efavirenz (EFV). Therefore, the test drug product manufacturing process was determined to be bilayer tablet to achieve sufficient stability of the drug product. The use of sodium lauryl sulfate (SLS) in the manufacturing process of efavirenz (EFV) granules is unavoidable, and based on the above results, tenofovir disoproxil fumarate (TDF) is incompatible in presence of efavirenz (EFV)+sodium lauryl sulfate (SLS). Hence, in this bilayer manufacturing process, tenofovir disoproxil fumarate (TDF)+lamivudine (LMV) will be in one layer, and efavirenz (EFV) will be in the other layer [12].

\section{Experimental design}

A Quality Target Product Profile (QTPP) for the new fixed-dose combination (FDC) bilayer drug product was set to achieve the desired quality, considering, safety and efficacy of the drug product. The quality targets were set considering the characterization of the single entity reference listed drug (RLD) product and general compendia standards. The objective of this development of a fixeddose combination of efavirenz (EFV), lamivudine (LMV), and tenofovir disoproxil fumarate (TDF) Tablets $600 \mathrm{mg} / 300 \mathrm{mg} / 300$ mg was to have a stable fixed-dose combination bilayer tablet, which is equivalent to the loose combination of comparator products that are VIREAD $\AA$ tablets $300 \mathrm{mg}$, EPIVIR $\AA$ tablets $300 \mathrm{mg}$ and SUSTIVA ${ }^{\circledR}$ tablets $600 \mathrm{mg}$ taken concomitantly. The product has been developed as a bilayer immediate release solid dosage form for oral administration with bilayer compression strategy considering efavirenz is layer-I and lamivudine and tenofovir disoproxil fumarate blend in layer-II.

Due to tenofovir disoproxil fumarate (TDF)+lamivudine (LMV)+efavirenz (EFV) are not compatible when mixed, a bilayer tablet, composed of one layer containing efavirenz (EFV) and the other layer containing tenofovir disoproxil fumarate (TDF)+lamivudine (LMV) was developed. The excipients were selected based on prior knowledge, excipients present in the single entity of reference listed drug product (RLD), and considering drugexcipient compatibility study.

The efavirenz (EFV) layer is prepared by using a wet granulation process to improve the flowability of the granule [13]. The tenofovir disoproxil fumarate/lamivudine (TFL) layer is prepared using a dry granulation process, to protect the tenofovir disoproxil fumarate (TDF) from degradation by absorbing moisture, as it is slightly hygroscopic [14]. During the formulation study, the manufacturing steps required to reach the quality target product profile were identified and proposed for process development. The initial proposal was to use similar qualitative compositions as those of individual reference standards [15-17], but the final composition and manufacturing method was selected based on the physicochemical characteristics of the product development. Based on literature search and previous experience, the proposed manufacturing procedure for the development was designed as below fig. 1.

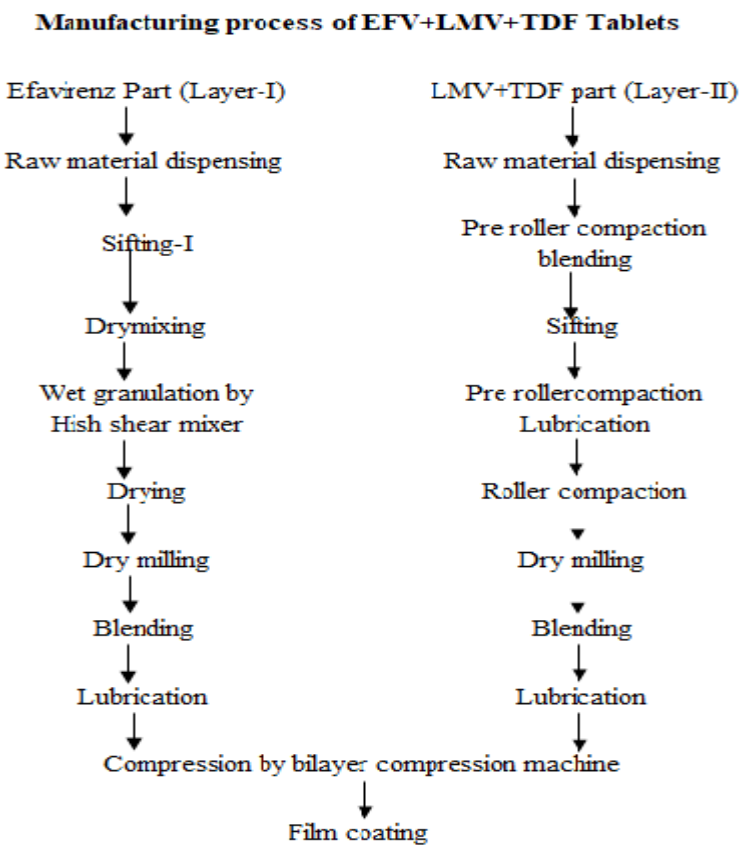

Fig. 1: Manufacturing process of FDC product

\section{Tooling details}

Based on the weight and size of individual reference drug product, bilayer tablets of the test formulation were targeted to $1550.00 \mathrm{mg}$ at the compression stage by using punch tooling of $21.20 \times 11.5 \mathrm{~mm}$ during the formulation and process development study.

\section{Formulation of efavirenz part (layer-I)}

The factors affecting the drug product critical quality attributes (CQAs) were investigated further based on the risk assessment (RA). It was designed to select the levels of sodium lauryl sulfate, hydroxypropyl cellulose, and croscarmellose sodium and magnesium stearate for efavirenz (EFV) layer optimization. In the case of the wet granulation process, the level of binder solution varies depending on the composition. If the composition of intra- granules was changed, the result may be distorted by the level of binder solution. For this reason, the major composition of the intra granule was fixed from ELT04 to ELT08. The levels of microcrystalline cellulose and croscarmellose sodium used in the intra granules were selected as $80 \mathrm{mg}$ and $30 \mathrm{mg}$, respectively. Sodium lauryl sulfate was used as a wetting agent and the level was investigated from $5.00 \mathrm{mg}$ to $12.00 \mathrm{mg}$.

Hydroxypropyl cellulose was used as a binder and the levels investigated ranged from $10.00 \mathrm{mg}$ to $25.00 \mathrm{mg}$. Extra granular croscarmellose sodium was used as a disintegrant and the levels investigated ranged from $15.00 \mathrm{mg}$ to $70.00 \mathrm{mg}$. Magnesium stearate was used as a lubricant and the levels investigated ranged from 8.00 $\mathrm{mg}$ to $12.00 \mathrm{mg}$. These levels are considered based on knowledge and inactive ingredient database (IID) levels and are within the 
recommended range in the handbook of pharmaceutical excipients $[18,19]$. Lactose monohydrate was used as a diluent and hydrophilic agent and it was used to adjust the weight of the tablet. Therefore, the level of lactose monohydrate would be changed according to the formulation variables. Formulation trials were carried out as bilayer tablets with a target weight of $1550.00 \mathrm{mg}$. while evaluation of efavirenz formulation, lamivudine, and tenofovir composition was kept constant to achieve the total weight. Further, the formulation variable's impact on dissolution was studied.

\section{Formulation of lamivudine (LMV)+tenofovir disoproxil fumarate (TDF) part (Layer-II)}

For formulation development, the dry granulation method was selected as the granulation process instead of wet granulation due to mitigating risk for hydrolysis of tenofovir disoproxil fumarate. The direct compression process was not selected due to flowability problems.

The selection of appropriate excipients was determined and confirmed by excipient compatibility studies and formulation studies. The selected excipients for the tenofovir disoproxil fumarate and lamivudine tablets formulation were similar to those used in single entity products. All selected excipients were commonly used in pharmaceutical oral dosage forms and were compliant with United States pharmacopoeia (USP) compendial requirements.

Tenofovir disoproxil fumarate and lamivudine have been classified as biopharmaceutics classification system (BCS) class III compounds displaying high aqueous solubility. The target is an immediate release fixed-dose combination tablet and the time to maximum plasma concentration (Tmax) of each reference listed drug (RLD) product is around 1 hour, so the target drug is expected to be dissolved in the stomach and absorbed in the upper small intestine when the suggested dissolution medium was used with low $\mathrm{pH}$. Therefore, equivalence with individual reference listed drug (RLD) was evaluated by dissolution study in $0.1 \mathrm{~N}$ hydrochloric acid $(\mathrm{HCl})$ medium. Tenofovir Disoproxil Fumarate and lamivudine have poor flowability as shown in the compressibility index (tenofovir disoproxil fumarate $(\mathrm{TDF})$ : value $=36$, poor, lamivudine (LMV): value $=34$, very poor) and hausner ratio (tenofovir disoproxil fumarate $(\mathrm{TDF})$ : value $=1.56$, poor, lamivudine $(\mathrm{LMV})$ : value $=1.52$, very poor) listed in table 4 . Poor flowability of drug substances may cause problems such as high weight and variable content uniformity of the drug product. Uneven blend distribution and bulk density may cause uneven filling of die cavities on the tablet press. Because of the poor flowability of tenofovir disoproxil fumarate and lamivudine, it is not suitable to use a direct compression process for tenofovir disoproxil fumarate and lamivudine tablets, especially when the ratio of active pharmaceutical ingredients (APIs) is high in the formulation.

The wet granulation process is commonly used to improve powder flowability and compatibility. However, tenofovir disoproxil fumarate has hydrolysis characteristics. Thus, the wet granulation process was also excluded.

Finally, the dry granulation process by roller compacting was chosen to improve the flowability and compatibility of tenofovir disoproxil fumarate. In the dry granulation process, by roller compacting, the particles of drug substances and excipients are aggregated by roller compaction to form a ribbon and then milled to produce granules by the oscillator. Enlargement of particles through the dry granulation process helps to have adequate flowability, density and compactibility that are particularly important characteristics for the high-speed production of tablets.

Table 1: Formulation trials of efavirenz part (layer-I)

\begin{tabular}{|c|c|c|c|c|c|c|c|c|c|}
\hline \multirow[t]{2}{*}{ S. No. } & \multirow[t]{2}{*}{ Ingredients } & ELT01 & ELT02 & ELT03 & ELT04 & ELT05 & ELT06 & ELT07 & ELT08 \\
\hline & & \multicolumn{8}{|l|}{ Mg } \\
\hline \multicolumn{10}{|c|}{ Intra granular materials } \\
\hline 1 & Efavirenz & 600.00 & 600.00 & 600.00 & 600.00 & 600.00 & 600.00 & 600.00 & 600.00 \\
\hline 2 & Microcrystalline cellulose & $\mathrm{N} / \mathrm{A}$ & $\mathrm{N} / \mathrm{A}$ & 130.00 & 130.00 & 130.00 & 130.00 & 130.00 & 130.00 \\
\hline 3 & Lactose monohydrate & 155.00 & 110.00 & $\mathrm{~N} / \mathrm{A}$ & 37.00 & $\mathrm{~N} / \mathrm{A}$ & $\mathrm{N} / \mathrm{A}$ & 20.00 & $\mathrm{~N} / \mathrm{A}$ \\
\hline 4 & Sodium lauryl sulfate & $\mathrm{N} / \mathrm{A}$ & $\mathrm{N} / \mathrm{A}$ & 5.00 & 8.00 & 12.00 & 12.00 & 10.00 & 10.00 \\
\hline 5 & Colloidal silicon dioxide & $\mathrm{N} / \mathrm{A}$ & $\mathrm{N} / \mathrm{A}$ & 10.00 & $\mathrm{~N} / \mathrm{A}$ & 4.00 & 4.00 & 4.00 & 6.00 \\
\hline 6 & Croscarmellose sodium & 22.00 & 20.00 & $\mathrm{~N} / \mathrm{A}$ & 30.00 & 30.00 & 30.00 & 30.00 & 30.00 \\
\hline 7 & Hydroxy propyl cellulose & 25.00 & 20.00 & 25.00 & 10.00 & 15.00 & 15.00 & 20.00 & 10.00 \\
\hline 8 & Purified water & 368.00 & 368.00 & 368.00 & 410.00 & 410.00 & 410.00 & 410.00 & 410.00 \\
\hline \multicolumn{10}{|c|}{ Extra granular materials } \\
\hline 9 & Croscarmellose sodium & 40.00 & 48.00 & 70.00 & 25.00 & 10.00 & 15.00 & 24.00 & 30.00 \\
\hline 10 & Microcrystalline cellulose & $\mathrm{N} / \mathrm{A}$ & 43.00 & $\mathrm{~N} / \mathrm{A}$ & $\mathrm{N} / \mathrm{A}$ & $\mathrm{N} / \mathrm{A}$ & $\mathrm{N} / \mathrm{A}$ & $\mathrm{N} / \mathrm{A}$ & $\mathrm{N} / \mathrm{A}$ \\
\hline 11 & Lactose monohydrate & $\mathrm{N} / \mathrm{A}$ & $\mathrm{N} / \mathrm{A}$ & $\mathrm{N} / \mathrm{A}$ & $\mathrm{N} / \mathrm{A}$ & 39.00 & 34.00 & $\mathrm{~N} / \mathrm{A}$ & 24.00 \\
\hline 12 & Magnesium Stearate & 8.00 & 9.00 & 10.00 & 10.00 & 10.00 & 10.00 & 12.00 & 10.00 \\
\hline Layer- & veight (mg) & 850.00 & 850.00 & 850.00 & 850.00 & 850.00 & 850.00 & 850.00 & 850.00 \\
\hline \multicolumn{10}{|c|}{ Layer-II (Lamivudine and tenofovir disoproxil fumarate) } \\
\hline 13 & $\begin{array}{l}\text { Tenofovir Disoproxil } \\
\text { Fumarate }\end{array}$ & 300.00 & 300.00 & 300.00 & 300.00 & 300.00 & 300.00 & 300.00 & 300.00 \\
\hline 14 & Microcrystalline cellulose & 10.00 & 10.00 & 10.00 & 10.00 & 10.00 & 10.00 & 10.00 & 10.00 \\
\hline 15 & Lactose monohydrate & 15.00 & 15.00 & 15.00 & 15.00 & 15.00 & 15.00 & 15.00 & 15.00 \\
\hline 16 & Croscarmellose sodium & 23.00 & 23.00 & 23.00 & 23.00 & 23.00 & 23.00 & 23.00 & 23.00 \\
\hline 17 & Magnesium Stearate & 2.00 & 2.00 & 2.00 & 2.00 & 2.00 & 2.00 & 2.00 & 2.00 \\
\hline \multicolumn{10}{|c|}{ Extra granular materials } \\
\hline 18 & Lamivudine & 300.00 & 300.00 & 300.00 & 300.00 & 300.00 & 300.00 & 300.00 & 300.00 \\
\hline 19 & $\begin{array}{l}\text { Lactose monohydrate and } \\
\text { powdered cellulose }\end{array}$ & 104.00 & 104.00 & 104.00 & 104.00 & 104.00 & 104.00 & 104.00 & 104.00 \\
\hline 20 & Croscarmellose sodium & 30.00 & 30.00 & 30.00 & 30.00 & 30.00 & 30.00 & 30.00 & 30.00 \\
\hline 21 & Colloidal silicon dioxide & 6.00 & 6.00 & 6.00 & 6.00 & 6.00 & 6.00 & 6.00 & 6.00 \\
\hline 22 & Magnesium Stearate & 10.00 & 10.00 & 10.00 & 10.00 & 10.00 & 10.00 & 10.00 & 10.00 \\
\hline Layer- & weight (mg) & 800.00 & 800.00 & 800.00 & 800.00 & 800.00 & 800.00 & 800.00 & 800.00 \\
\hline Total v & ight of core tablets & 1650.00 & 1650.00 & 1650.00 & 1650.00 & 1650.00 & 1650.00 & 1650.00 & 1650.00 \\
\hline \multicolumn{10}{|c|}{ Film coating } \\
\hline 23 & Opadry white & 38.00 & 38.00 & 38.00 & 38.00 & 38.00 & 38.00 & 38.00 & 38.00 \\
\hline 24 & Purified water & 215.00 & 215.00 & 215.00 & 215.00 & 215.00 & 215.00 & 215.00 & 215.00 \\
\hline 25 & $\begin{array}{l}\text { Total weight of coated } \\
\text { tablets }\end{array}$ & 1688.00 & 1688.00 & 1688.00 & 1688.00 & 1688.00 & 1688.00 & 1688.00 & 1688.00 \\
\hline
\end{tabular}


As per the compatibility study and reference listed drug (RLD) composition, all the excipients were considered for the formulation development. Based on the literature, patents data, and previous experience, the total target weight was fixed. While developing the lamivudine and tenofovir formulations, the optimum formulation of efavirenz was used and it was kept constant to achieve the target weight of core tablet such as $1550.00 \mathrm{mg}$. Generally consideration of bilayer compression, layer-I weight should be higher than layer-II. Hence, layer-I and layer-II was fixed. Film coating was performed for each formulation with target weight buildup of $2.3 \% \mathrm{w} / \mathrm{w}$ with $15 \%$ of solid concentration. Each formulation, in-process and finished product characteristics were verified to compare with the reference product.

Table 2: Formulation trials of lamivudine and tenofovir disoproxil fumarate part (layer-II)

\begin{tabular}{|c|c|c|c|c|c|c|c|c|c|}
\hline \multirow{2}{*}{$\begin{array}{l}\text { S. } \\
\text { No. }\end{array}$} & \multirow[t]{2}{*}{ Ingredients } & ELT09 & ELT10 & ELT11 & ELT12 & ELT13 & ELT14 & ELT15 & ELT16 \\
\hline & & \multicolumn{8}{|l|}{ Mg } \\
\hline \multicolumn{10}{|c|}{ Intra granular materials } \\
\hline 1 & Efavirenz & 600.00 & 600.00 & 600.00 & 600.00 & 600.00 & 600.00 & 600.00 & 600.00 \\
\hline 2 & Microcrystalline cellulose & 130.00 & 130.00 & 130.00 & 130.00 & 130.00 & 130.00 & 130.00 & 130.00 \\
\hline 3 & Sodium lauryl sulfate & 10.00 & 10.00 & 10.00 & 10.00 & 10.00 & 10.00 & 10.00 & 10.00 \\
\hline 4 & Colloidal silicon dioxide & 6.00 & 6.00 & 6.00 & 6.00 & 6.00 & 6.00 & 6.00 & 6.00 \\
\hline 5 & Croscarmellose sodium & 30.00 & 30.00 & 30.00 & 30.00 & 30.00 & 30.00 & 30.00 & 30.00 \\
\hline 6 & Hydroxy propyl cellulose & 10.00 & 10.00 & 10.00 & 10.00 & 10.00 & 10.00 & 10.00 & 10.00 \\
\hline 7 & Purified water & 410.00 & 410.00 & 410.00 & 410.00 & 410.00 & 410.00 & 410.00 & 410.00 \\
\hline \multicolumn{10}{|c|}{ Extra granular materials } \\
\hline 8 & Croscarmellose sodium & 30.00 & 30.00 & 30.00 & 30.00 & 30.00 & 30.00 & 30.00 & 30.00 \\
\hline 9 & Lactose monohydrate & 24.00 & 24.00 & 24.00 & 24.00 & 24.00 & 24.00 & 24.00 & 24.00 \\
\hline 10 & Magnesium Stearate & 10.00 & 10.00 & 10.00 & 10.00 & 10.00 & 10.00 & 10.00 & 10.00 \\
\hline Lay & weight (mg) & 850.00 & 850.00 & 850.00 & 850.00 & 850.00 & 850.00 & 850.00 & 850.00 \\
\hline \multicolumn{10}{|c|}{ Layer-II (Lamivudine and tenofovir disoproxil fumarate) } \\
\hline 11 & $\begin{array}{l}\text { Tenofovir Disoproxil } \\
\text { Fumarate }\end{array}$ & 300.00 & 300.00 & 300.00 & 300.00 & 300.00 & 300.00 & 300.00 & 300.00 \\
\hline 12 & Microcrystalline cellulose & $\mathrm{N} / \mathrm{A}$ & 23.00 & 25.00 & 48.00 & 25.00 & $\mathrm{~N} / \mathrm{A}$ & 25.00 & 10.00 \\
\hline 13 & Lactose monohydrate & 23.00 & $\mathrm{~N} / \mathrm{A}$ & 23.00 & $\mathrm{~N} / \mathrm{A}$ & 23.00 & 23.00 & $\mathrm{~N} / \mathrm{A}$ & 15.00 \\
\hline 14 & Croscarmellose sodium & 25.00 & 25.00 & $\mathrm{~N} / \mathrm{A}$ & $\mathrm{N} / \mathrm{A}$ & $\mathrm{N} / \mathrm{A}$ & 25.00 & 23.00 & 23.00 \\
\hline 15 & Colloidal silicon dioxide & $\mathrm{N} / \mathrm{A}$ & N/A & $\mathrm{N} / \mathrm{A}$ & $\mathrm{N} / \mathrm{A}$ & $\mathrm{N} / \mathrm{A}$ & 2.00 & 2.00 & $\mathrm{~N} / \mathrm{A}$ \\
\hline 16 & Magnesium Stearate & 2.00 & 2.00 & 2.00 & 2.00 & 2.00 & $\mathrm{~N} / \mathrm{A}$ & $\mathrm{N} / \mathrm{A}$ & 2.00 \\
\hline \multicolumn{10}{|c|}{ Extra granular materials } \\
\hline 17 & Lamivudine & 300.00 & 300.00 & 300.00 & 300.00 & 300.00 & 300.00 & 300.00 & 300.00 \\
\hline 18 & $\begin{array}{l}\text { Lactose monohydrate and } \\
\text { powdered cellulose }\end{array}$ & $\mathrm{N} / \mathrm{A}$ & $\mathrm{N} / \mathrm{A}$ & $\mathrm{N} / \mathrm{A}$ & 100.00 & 100.00 & 60.00 & 120.00 & 104.00 \\
\hline 19 & Lactose monohydrate & 100.00 & $\mathrm{~N} / \mathrm{A}$ & 50.00 & $\mathrm{~N} / \mathrm{A}$ & $\mathrm{N} / \mathrm{A}$ & $\mathrm{N} / \mathrm{A}$ & $\mathrm{N} / \mathrm{A}$ & $\mathrm{N} / \mathrm{A}$ \\
\hline 20 & Microcrystalline cellulose & $\mathrm{N} / \mathrm{A}$ & 96.00 & 46.00 & N/A & $\mathrm{N} / \mathrm{A}$ & 40.00 & N/A & $\mathrm{N} / \mathrm{A}$ \\
\hline 21 & Croscarmellose sodium & 36.00 & 40.00 & 40.00 & 36.00 & 28.00 & 38.00 & 20.00 & 30.00 \\
\hline 22 & Colloidal silicon dioxide & 6.00 & 6.00 & 6.00 & 4.00 & 10.00 & $\mathrm{~N} / \mathrm{A}$ & $\mathrm{N} / \mathrm{A}$ & 6.00 \\
\hline 23 & Magnesium Stearate & 8.00 & 8.00 & 8.00 & 10.00 & 12.00 & 12.00 & 10.00 & 10.00 \\
\hline Lay & I weight (mg) & 800.00 & 800.00 & 800.00 & 800.00 & 800.00 & 800.00 & 800.00 & 800.00 \\
\hline Tot & eight of core tablets & 1650.00 & 1650.00 & 1650.00 & 1650.00 & 1650.00 & 1650.00 & 1650.00 & 1650.00 \\
\hline \multicolumn{10}{|c|}{ Film coating } \\
\hline 24 & Opadry white & 38.00 & 38.00 & 38.00 & 38.00 & 38.00 & 38.00 & 38.00 & 38.00 \\
\hline 25 & Purified water & 215.00 & 215.00 & 215.00 & 215.00 & 215.00 & 215.00 & 215.00 & 215.00 \\
\hline 26 & $\begin{array}{l}\text { Total weight of coated } \\
\text { Tablets }\end{array}$ & 1688.00 & 1688.00 & 1688.00 & 1688.00 & 1688.00 & 1688.00 & 1688.00 & 1688.00 \\
\hline
\end{tabular}

Table 3: Process parameters used for the manufacturing process

\begin{tabular}{|c|c|c|c|c|c|c|}
\hline \multicolumn{4}{|c|}{ Layer-1 (efavirenz) } & \multicolumn{3}{|c|}{ Layer-II (lamivudine and tenofovir disoproxil fumarate) } \\
\hline \multicolumn{4}{|c|}{ Wet granulation process } & \multicolumn{3}{|c|}{ Direct blending process/roller compaction } \\
\hline \multicolumn{2}{|c|}{ Process step } & \multicolumn{2}{|l|}{ Parameters } & \multirow{4}{*}{$\begin{array}{l}\text { Process step } \\
\text { Pre roller compaction blending }\end{array}$} & \multicolumn{2}{|l|}{ Parameters } \\
\hline Dry mixing & & Dry mixing time & $10 \mathrm{~min}$ & & Blending time & $10 \mathrm{~min}$ \\
\hline & & Impeller speed & 95RPM & & & \\
\hline & & Chopper speed & 1500RPM & & & \\
\hline \multirow[t]{6}{*}{ Granulation } & $\begin{array}{l}\text { Binder } \\
\text { addition }\end{array}$ & Binder addition time & $10 \mathrm{~min}$ & $\begin{array}{l}\text { Pre roller compaction } \\
\text { lubrication }\end{array}$ & Lubrication time & $5 \mathrm{~min}$ \\
\hline & & Impeller speed & 95RPM & Roller compaction & Roller speed & 5-10RPM \\
\hline & & Chopper speed & 1500RPM & & Roller gap & $2.0-4.0 \mathrm{~mm}$ \\
\hline & Kneading & Kneading time & $5 \mathrm{~min}$ & & Feed augur speed & $0-15 R P M$ \\
\hline & & Impeller speed & 115RPM & & Roller force & $2-7 \mathrm{bar}$ \\
\hline & & Chopper speed & 2500RPM & & & \\
\hline \multirow{2}{*}{\multicolumn{2}{|c|}{ Wet milling }} & Wet milling speed & 1500RPM & $\mathrm{N} / \mathrm{A}$ & & \\
\hline & & Screen size & $5.0 \mathrm{~mm}$ & & & \\
\hline \multirow[t]{2}{*}{ Drying } & & Inlet temp & $60 \pm 10^{\circ} \mathrm{C}$ & & & \\
\hline & & LOD & NMT $2.5 \%$ & & & \\
\hline \multirow{2}{*}{\multicolumn{2}{|c|}{ Dry milling }} & Mill speed & 500RPM & Dry milling & Mill speed & 1000RPM \\
\hline & & Screen size & $2.0 \mathrm{~mm}$ & & Screen size & $1.0 \mathrm{~mm}$ \\
\hline \multicolumn{2}{|l|}{ Blending } & Blending time & $10 \mathrm{~min}$ & Blending & Blending time & $10 \mathrm{~min}$ \\
\hline \multicolumn{2}{|l|}{ Lubrication } & Lubrication time & $5 \min$ & Lubrication & Lubrication time & $5 \mathrm{~min}$ \\
\hline
\end{tabular}


By considering two active substances in the formulation, formulation tenofovir disoproxil fumarate (TDF) was used for the roller compaction and lamivudine, with other extra materials recommended to add at the blending stage. The roller compaction process followed by direct blending of layer-II yielded consistency content uniformity and assay results after compression of bilayer tablets. Further, all the in-process and finished product characteristics were verified after all the formulation trials.

The level of microcrystalline cellulose may affect the assay, content uniformity, and dissolution, and compressibility index (CI) values. Microcrystalline cellulose was used as a diluent and the levels investigated ranged from $0.00 \mathrm{mg}$ to $119.00 \mathrm{mg}$. The level of croscarmellose sodium may affect the dissolution and friability. Croscarmellose sodium was used as a disintegrant and the levels investigated ranged from $28.00 \mathrm{mg}$ to $63.00 \mathrm{mg}$. Lactose monohydrate investigated ranged from $0.00 \mathrm{mg}$ to $123.00 \mathrm{mg}$ and powdered cellulose was used as a diluent to adjust the weight of the tablet. The investigated are ranged from $0.00 \mathrm{mg}$ to $130.00 \mathrm{mg}$. Colloidal silicon dioxide and magnesium stearate were changed to improve the flow properties of the final blend and avoid the sticking of core tablets during bi-layer compression. Because it was expected to have the least impact on the critical quality attributes (CQAs) among the selected excipients. Therefore, the amount of these excipients would be changed accordingly when the level of the factors was changed These levels are considered based on the knowledge and inactive ingredient database (IID) level and are within the recommended range in the handbook of Pharmaceutical Excipients [18, 19]. The detailed process parameters used for the execution of formulation trials were mentioned in table 3 .

\section{RESULTS}

From the physical evaluation of active substances data, it is evident that the tenofovir disoproxil fumarate (TDF) and lamivudine (LMV) active pharmaceutical ingredients (APIs) have very poor flow properties. In the case of efavirenz (EFV), though the bulk density (BD) result is very low, the flowability character is passable. The angle of repose test for each active pharmaceutical ingredient (API) was unable to measure because the flow of each active pharmaceutical ingredient (API) was impossible to measure in the flowability tester.

Table 4: Physical property results of active pharmaceutical ingredients (APIs) ${ }^{*}$

\begin{tabular}{|c|c|c|c|c|c|}
\hline Batch No. & $\begin{array}{l}\text { Bulk density } \\
(\mathrm{g} / \mathrm{ml})\end{array}$ & $\begin{array}{l}\text { Tapped density } \\
\text { (g/ml) }\end{array}$ & $\begin{array}{l}\text { Compressibility index } \\
\text { (CI)*(\%) }\end{array}$ & $\begin{array}{l}\text { Hausner ration } \\
\text { (HR)** }\end{array}$ & Flow character \\
\hline $\begin{array}{l}\text { Tenofovir Disoproxil } \\
\text { Fumarate }\end{array}$ & $0.3261 \pm 0.02$ & $0.5095 \pm 0.01$ & $36 \pm 0.03$ & $1.56 \pm 0.01$ & Very poor \\
\hline Lamivudine & $0.5318 \pm 0.01$ & $0.8057 \pm 0.01$ & $34 \pm 0.01$ & $1.52 \pm 0.02$ & Very poor \\
\hline Efavirenz & $0.2266 \pm 0.02$ & $0.2981 \pm 0.02$ & $24 \pm 0.06$ & $1.32 \pm 0.01$ & Passable \\
\hline
\end{tabular}

$*_{\mathrm{n}}=3$, mean $\pm \mathrm{SD}$

\section{Compressibility index (CI)}

The simplest way of measuring the free flow property of a powder is compressibility, an indication of the ease with which a material can be induced to flow given by $\%$ compressibility index (\% CI). It can be calculated from the unsettled apparent volume, $\mathrm{P}$ bulk, and the final tapped volume, $\mathrm{p}_{\text {tapped, }}$ of the powder after tapping the material until no further volume changes occur.

$$
\text { Compressibility Index }(\mathrm{CI})=\frac{\rho_{\text {tap }}-\rho_{\text {bulk }}}{\rho_{\text {tap }}} \times 100
$$

Hausner ratio may be calculated using measured values for bulk and tapped density. (tapped density and bulk density $(\mathrm{g} / \mathrm{ml}$ )

$$
\text { Hausner Ratio }(\mathrm{HR})=\frac{\rho_{\text {tap }}}{\rho_{\text {bulk }}}
$$

Table 5: Flow properties according to carr's index and hausner ratio

\begin{tabular}{lll}
\hline Consolidation index (carr's \%) & Flow & Hausner's ratio \\
\hline$\geq 10$ & Excellent & $1.00-1.11$ \\
$11-15$ & Good & $1.12-1.18-$ \\
$16-20$ & Fair & $1.19-1.25$ \\
$21-25$ & Passable & $1.26-1.34$ \\
$26-31$ & Poor & $1.35-1.45$ \\
$32-37$ & Very poor & $1.46-1.59$ \\
$>38$ & Very, very poor & $>1.6$ \\
\hline
\end{tabular}

\section{Angle of repose}

The Angle of repose is defined as the maximum angle possible between the surfaces of a pile of powder and the horizontal plane. This was determined by passing required quantities of drug granules through a funnel from a particular height $(2 \mathrm{~cm})$ onto a flat surface until it formed a heap, which touched the tip of the funnel. Experiments for the angle of repose were not measured because of very, very poor flow of drug substances, and heap were not formed to the tip of the funnel.

\section{Particle size distribution (PSD data) for active substances}

The particle size of each tenofovir disoproxil fumarate (TDF) and lamivudine (LMV) active pharmaceutical ingredients (API's) was determined by using CILAS particle size analyzer at 2000 mbar dispensing pressure and efavirenz (EFV) active pharmaceutical ingredient (API) was determined by using CILAS particle size analyzer at $500 \mathrm{~m}$ bar dispensing pressure and results are mentioned below.

\begin{tabular}{|c|c|c|c|}
\hline Batch No. & Height (mm) & Angle of repose $(\theta)$ & Flow character \\
\hline Tenofovir Disoproxil Fumarate & Impossible to measure & Impossible to measure & $\mathrm{N} / \mathrm{A}$ \\
\hline Lamivudine & Impossible to measure & Impossible to measure & $\mathrm{N} / \mathrm{A}$ \\
\hline Efavirenz & Impossible to measure & Impossible to measure & $\mathrm{N} / \mathrm{A}$ \\
\hline
\end{tabular}

Table 6: Flow properties of active pharmaceutical ingredients (APIs) 
Table 7: Particle size distribution results of active pharmaceutical ingredients (APIs)

\begin{tabular}{lccc}
\hline $\mathbf{d ~} \mathbf{1 0}(\boldsymbol{\mu m})$ & $\mathbf{d ~ 5 0}(\boldsymbol{\mu m})$ & $\mathbf{d ~ 9 0}(\boldsymbol{\mu m})$ & Mean particle size $(\boldsymbol{\mu m})$ \\
\hline $\begin{array}{l}\text { Tenofovir Disoproxil Fumarate } \\
1.42 \pm 2.24\end{array}$ & $6.36 \pm 3.28$ & $27.29 \pm 2.22$ & 11.69 \\
$\begin{array}{l}\text { Lamivudine } \\
22.42 \pm 1.28\end{array}$ & $58.96 \pm 4.28$ & $96.93 \pm 3.14$ & 59.44 \\
Efavirenz & & & \\
$0.62 \pm 0.18$ & $1.95 \pm 2.28$ & $3.42 \pm 4.15$ & 2.00 \\
\hline
\end{tabular}

$*^{n}=3$ mean \pm SD

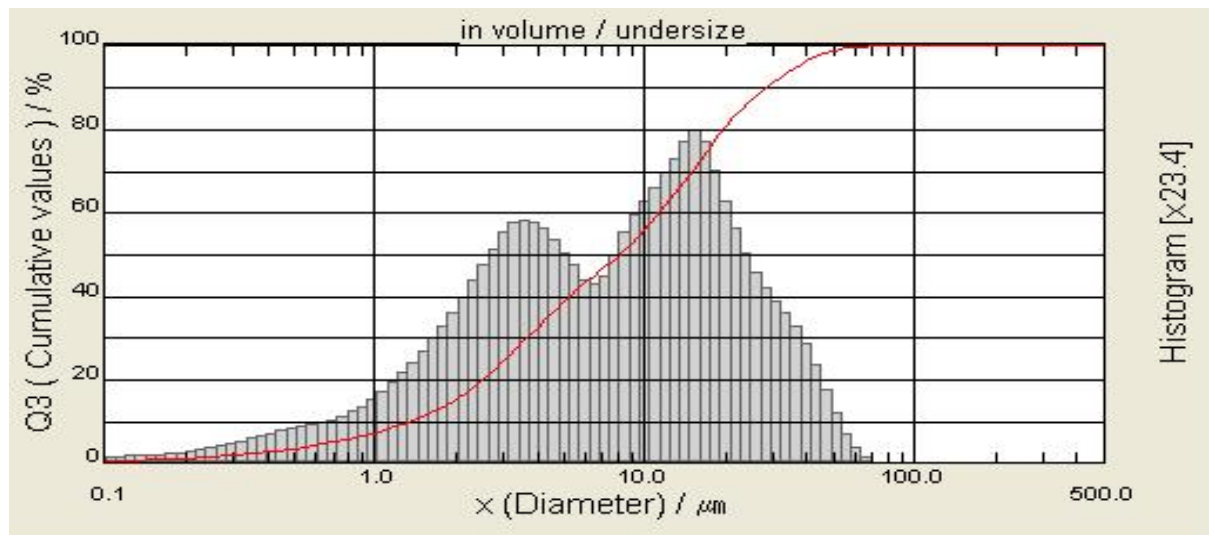

Fig. 2: Particle size (PSD data) of tenofovir disoproxil fumarate. The data is expressed as mean $\pm S D, n=3$

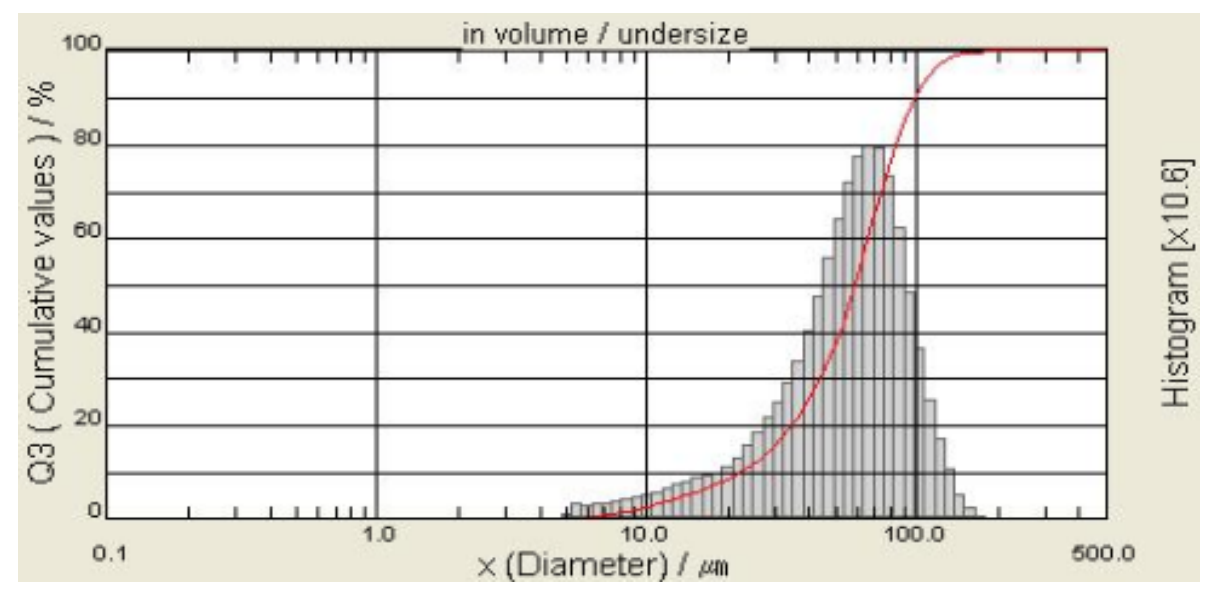

Fig. 3: Particle size data (PSD data) of lamivudine. The data is expressed as mean $\pm S D, n=3$

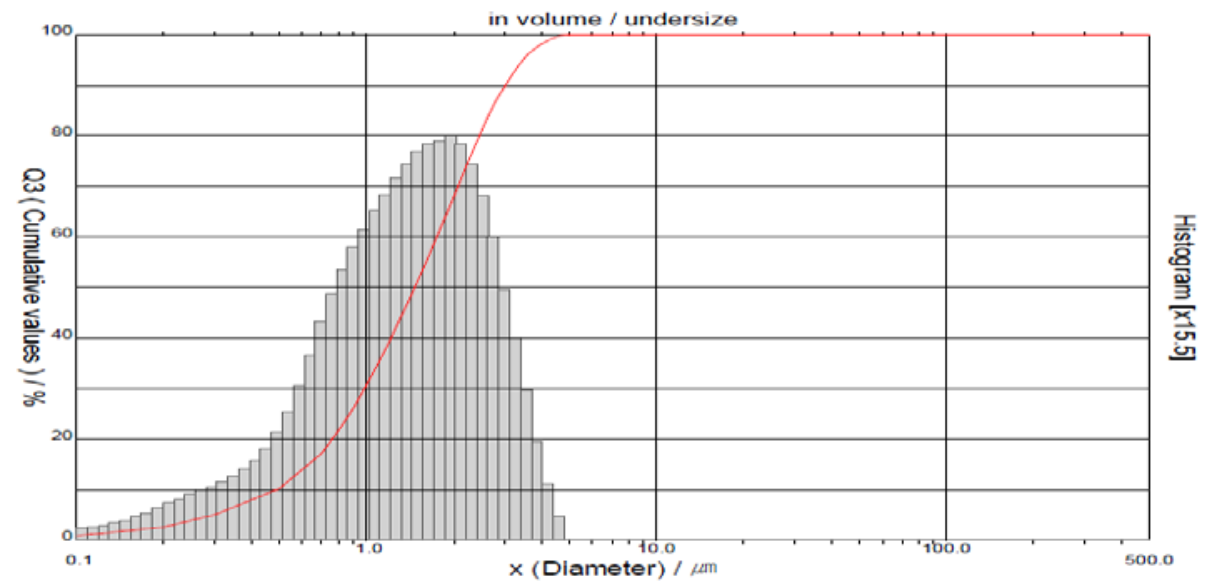

Fig. 4: Particle size data (PSD data) of efavirenz. The data is expressed as mean $\pm S D, n=3$ 


\section{Solubility studies}

Tenofovir disoproxil fumarate (TDF) is categorized under the biopharmaceutics classification system (BCS) class III compound (high soluble and low permeable). In this test, tenofovir disoproxil fumarate (TDF) exhibits $\mathrm{pH}$-dependent solubility at $37{ }^{\circ} \mathrm{C}$. Tenofovir disoproxil fumarate (TDF) is soluble in $0.1 \mathrm{~N}$ hydrochloric acid $(\mathrm{HCl})$ and sparingly soluble in $\mathrm{pH} 4.5$ acetate buffer and $\mathrm{pH} 6.8$ phosphate buffer based on the United states pharmacopeia (USP) solubility scale. Lamivudine (LMV) is categorized under the biopharmaceutics classification system (BCS) class III compound (high, soluble and lowpermeable). In this test, lamivudine (LMV) exhibits $\mathrm{pH}$-independent solubility at $37{ }^{\circ} \mathrm{C}$. Lamivudine (LMV) is freely soluble in $0.1 \mathrm{~N}$ hydrochloric acid $(\mathrm{HCl}), \mathrm{pH} 4.5$ acetate buffer, and $\mathrm{pH} 6.8$ phosphate buffer. The solubility study results were interpreted based on the United States pharmacopeia (USP) solubility scale. Efavirenz (EFV) is categorized under biopharmaceutics classification system (BCS) class II or IV compound (Low soluble). In this test, efavirenz (EFV) exhibits pH-independent solubility at $37{ }^{\circ} \mathrm{C}$. Efavirenz (EFV) is practically insoluble in $0.1 \mathrm{~N}$ hydrochloric acid ( $\mathrm{HCl}), \mathrm{pH} 4.5$ acetate buffer, $\mathrm{pH} 6.8$ phosphate buffer and in purified water. Results of the solubility study were interpreted based on the United States pharmacopeia (USP) solubility scale [20]. Based on the solubility studies of three active substances, dissolution methods such as purified water with $1.0 \%$ sodium lauryl sulfate (SLS) for efavirenz and $0.1 \mathrm{~N}$ hydrochloric acid (HCL) for lamivudine and tenofovir disoproxil fumarate were selected.

Table 8: Solubility in various media at $37^{\circ} \mathrm{C}$

\begin{tabular}{|c|c|c|c|c|}
\hline $\begin{array}{l}\text { Medium/Buffer } \\
\left(100 \mathrm{ml} \text { at } 37^{\circ} \mathrm{C}\right)\end{array}$ & $\begin{array}{l}\text { Solubility } \\
\text { (mg/ml) }\end{array}$ & $\begin{array}{l}\text { Dose solubility } \\
\text { volume }(\mathrm{ml})\end{array}$ & $\begin{array}{l}\text { Part of solvent required } \\
\text { for } 1 \text { Part of Solute }\end{array}$ & $\begin{array}{l}\text { Descriptive term united states } \\
\text { pharmacopeia (USP) }\end{array}$ \\
\hline \multicolumn{5}{|l|}{ Efavirenz } \\
\hline $0.1 \mathrm{~N} \mathrm{HCl}$ & $0.014 \pm 0.03$ & 42,857 & 71,429 & Practically insoluble \\
\hline pH 4.5 acetate buffer & $0.022 \pm 0.19$ & 27,273 & 45,455 & Practically insoluble \\
\hline pH 6.8 phosphate buffer & $0.013 \pm 0.23$ & 46,154 & 76,923 & Practically insoluble \\
\hline Purified Water & $0.015 \pm 0.16$ & 40,000 & 66,667 & Practically insoluble \\
\hline Purified Water with $0.5 \%$ SLS & $0.918 \pm 0.08$ & 654 & 1090 & Very slightly soluble \\
\hline Purified Water with $1 \%$ SLS & $2.229 \pm 0.15$ & 269 & 449 & Slightly soluble \\
\hline Purified Water with $2 \%$ SLS & $4.650 \pm 0.07$ & 129 & 215 & Slightly soluble \\
\hline \multicolumn{5}{|l|}{ Tenofovir Disoproxil Fumarate } \\
\hline $0.1 \mathrm{~N} \mathrm{HCl}$ & $43.530 \pm 0.11$ & 7 & 23 & soluble \\
\hline $\mathrm{pH} 4.5$ acetate buffer & $22.894 \pm 0.15$ & 13 & 44 & sparingly soluble \\
\hline pH 6.8 phosphate buffer & $15.735 \pm 0.04$ & 19 & 64 & sparingly soluble \\
\hline \multicolumn{5}{|l|}{ Lamivudine } \\
\hline $0.1 \mathrm{~N} \mathrm{HCl}$ & $185.778 \pm 0.03$ & 2 & 5 & freely soluble \\
\hline pH 4.5 acetate buffer & $168.693 \pm 0.09$ & 2 & 6 & freely soluble \\
\hline pH 6.8 phosphate buffer & $153.677 \pm 0.06$ & 2 & 7 & freely soluble \\
\hline
\end{tabular}

${ }^{*} \mathrm{n}=3$, mean $\pm \mathrm{SD}$

Table 9: United States pharmacopeia (USP) solubility scale

\begin{tabular}{ll}
\hline Descriptive term & Parts of solvent required for 1 part of solute \\
\hline Very soluble & Less than 1 \\
Freely soluble & From 1 to 10 \\
Soluble & From 10 to 30 \\
Sparingly soluble & From 30 to 100 \\
Slightly soluble & From 100 to 1000 \\
Very slightly soluble & From 1000 to 10,000 \\
Practically insoluble, or Insoluble & 10,000 and over \\
\hline
\end{tabular}

Table 10: Final blend physical characteristics-efavirenz part (layer-I)*

\begin{tabular}{|c|c|c|c|c|c|}
\hline Batch No. & Bulk density (g/ml) & Tapped density $(\mathrm{g} / \mathrm{ml})$ & Compressibility index (\%) & Hausner's ratio & LOD (\%) \\
\hline ELT01 & $0.62 \pm 0.02$ & $0.76 \pm 0.01$ & $18 \pm 0.08$ & $0.82 \pm 0.02$ & 1.52 \\
\hline ELT02 & $0.57 \pm 0.03$ & $0.71 \pm 0.05$ & $19 \pm 0.011$ & $1.24 \pm 0.03$ & 1.92 \\
\hline ELT03 & $0.64 \pm 0.01$ & $0.80 \pm 006$ & $20 \pm 0.12$ & $1.25 \pm 0.02$ & 1.78 \\
\hline ELT04 & $0.55 \pm 0.08$ & $0.69 \pm 0.04$ & $20 \pm 0.12$ & $1.25 \pm 0.01$ & 2.02 \\
\hline ELT05 & $0.59 \pm 0.04$ & $0.74 \pm 0.06$ & $20 \pm 0.01$ & $1.25 \pm 0.06$ & 2.40 \\
\hline ELT06 & $0.61 \pm 0.01$ & $0.78 \pm 006$ & $22 \pm 0.12$ & $1.28 \pm 0.02$ & 1.58 \\
\hline ELT07 & $0.58 \pm 0.04$ & $0.76 \pm 0.02$ & $24 \pm 0.13$ & $1.31 \pm 0.06$ & 1.46 \\
\hline ELT08 & $0.56 \pm 0.01$ & $0.67 \pm 006$ & $16 \pm 0.12$ & $1.20 \pm 0.02$ & 1.58 \\
\hline
\end{tabular}

${ }^{*} \mathrm{n}=3$, mean $\pm \mathrm{SD}$

Table 11: Final blend physical characteristics (lamivudine and tenofovir disoproxil fumarate part (layer-II)*

\begin{tabular}{|c|c|c|c|c|c|}
\hline Batch No. & Bulk density $(\mathrm{g} / \mathrm{ml})$ & Tapped density $(\mathrm{g} / \mathrm{ml})$ & Compressibility index (\%) & Hausner's ratio & LOD (\%) \\
\hline ELT09 & $0.55 \pm 0.01$ & $0.69 \pm 0.004$ & $21 \pm 0.12$ & $1.27 \pm 0.02$ & 1.02 \\
\hline ELT10 & $0.57 \pm 0.02$ & $0.73 \pm 0.001$ & $21 \pm 0.05$ & $1.27 \pm 0.01$ & 1.20 \\
\hline ELT11 & $0.59 \pm 0.01$ & $0.76 \pm 0.002$ & $23 \pm .0 .04$ & $1.30 \pm 0.01$ & 1.18 \\
\hline ELT12 & $0.60 \pm 0.06$ & $0.74 \pm 0.001$ & $19 \pm 0.03$ & $1.23 \pm 0.03$ & 1.50 \\
\hline ELT13 & $0.60 \pm 0.01$ & $0.74 \pm 0.002$ & $19 \pm 0.14$ & $1.23 \pm 0.04$ & 1.45 \\
\hline ELT14 & $0.52 \pm 0.03$ & $0.69 \pm 0.001$ & $25 \pm 0.08$ & $1.33 \pm 0.05$ & 1.62 \\
\hline ELT15 & $0.58 \pm 0.04$ & $0.75 \pm 0.004$ & $22 \pm 0.11$ & $1.29 \pm 0.02$ & 1.50 \\
\hline ELT16 & $0.55 \pm 0.02$ & $0.71 \pm 0.002$ & $22 \pm 0.02$ & $1.28 \pm 0.01$ & 1.11 \\
\hline
\end{tabular}

${ }^{*} \mathrm{n}=3$, mean $\pm \mathrm{SD}$ 


\section{Physical property of final blend}

The flowability of the final blend for layer-I (efavirenz part) and layer-II (lamivudine and tenofovir disoproxil fumarate part in table 10 and table 11 indicate fair to passable as per the united states pharmacopoeia (USP) flow property guidance and there is no flowability issues was observed during the bilayer compression. Further, loss on drying (LOD) of final blends was maintained within the limit of not more than (NMT) $2.5 \% \mathrm{w} / \mathrm{w}$.

\section{Bilayer compression results}

Bilayer compression was carried out by using parle elizabeth compression machine with 10 station by using punch tooling of $21.20 \times 11.5 \mathrm{~mm}$. All the compression process parameters and physical parameters were evaluated during the formulation trials from ELT01 to ELT16 and are presented in table 12. The physical appearance of the compressed tablets was satisfactory. All the formulation study were carried out by using a hardness range of 18$28 \mathrm{kP}$ during the compression stage.

\section{Polymorphism}

The polymorphic study was carried out for the three active pharmaceutical ingredients (APIs) such as efavirenz, lamivudine, and tenofovir and confirmed that these drug substances comply Form-1 (efavirenz and tenofovir) and Form-II for lamivudine by considering the 2-theta values. Further, these polymorphic forms were reconfirmed from the finished drug product as per fig. 5-10, and which indicates that the manufacturing process has no impact on the polymorphic character of the three-drug substances. It can also conclude that there is no interaction between active substances for the bi-layer formulation.

Table 12: Compression parameters and physical parameters of the core tablets

\begin{tabular}{|c|c|c|c|c|c|c|c|c|c|c|c|c|c|c|c|c|c|}
\hline \multicolumn{2}{|c|}{ Parameters * } & $\begin{array}{l}\text { ELT } \\
01\end{array}$ & $\begin{array}{l}\text { ELT } \\
02\end{array}$ & $\begin{array}{l}\text { ELT } \\
03\end{array}$ & $\begin{array}{l}\text { ELT } \\
04\end{array}$ & $\begin{array}{l}\text { ELT } \\
05\end{array}$ & $\begin{array}{l}\text { ELT0 } \\
6\end{array}$ & $\begin{array}{l}\text { ELT0 } \\
7\end{array}$ & $\begin{array}{l}\text { ELT0 } \\
8\end{array}$ & $\begin{array}{l}\text { ELT0 } \\
9\end{array}$ & $\begin{array}{l}\text { ELT1 } \\
0\end{array}$ & $\begin{array}{l}\text { ELT1 } \\
1\end{array}$ & $\begin{array}{l}\text { ELT1 } \\
2\end{array}$ & $\begin{array}{l}\text { ELT1 } \\
3\end{array}$ & $\begin{array}{l}\text { ELT1 } \\
4\end{array}$ & $\begin{array}{l}\text { ELT1 } \\
5\end{array}$ & $\begin{array}{l}\text { ELT1 } \\
6\end{array}$ \\
\hline \multicolumn{2}{|l|}{ Turret speed } & \multirow{2}{*}{\multicolumn{16}{|c|}{10 RPM (efavirenz part) }} \\
\hline Feeder & $\mathrm{S} 1$ & & & & & & & & & & & & & & & & \\
\hline speed & S2 & $10 \mathrm{RPN}$ & (lamiv & line and & enofov & disopr & il fumar & e part) & & & & & & & & & \\
\hline \multirow{5}{*}{$\begin{array}{l}\text { Fill depth } \\
(\mathrm{mm})\end{array}$} & S1 & 4.80 & 5.05 & 6.01 & 5.98 & 4.95 & $6.02 \pm$ & $6.75 \pm$ & $6.02 \pm$ & $6.15 \pm$ & $6.40 \pm$ & $6.10 \pm$ & $6.18 \pm$ & $6.24 \pm$ & $6.21 \pm$ & $5.95 \pm$ & $6.01 \pm$ \\
\hline & & $\begin{array}{l} \pm \\
0.3\end{array}$ & \pm & $\begin{array}{l} \pm \\
0.3\end{array}$ & $\begin{array}{l} \pm \\
0.4\end{array}$ & \pm & 0.3 & 0.25 & 0.3 & 0.3 & 0.6 & 0.5 & 0.1 & 0.8 & 0.4 & 0.2 & 0.24 \\
\hline & S2 & 13.9 & 12.9 & 13.4 & 12.6 & 13.8 & 11.90 & 13.90 & 13.60 & 13.80 & 12.40 & 13.10 & 12.90 & 13.22 & 13.18 & 13.20 & 13.80 \\
\hline & & $0 \pm$ & $0 \pm$ & $0 \pm$ & $0 \pm$ & $0 \pm$ & \pm & \pm & \pm & \pm & \pm & \pm & \pm & \pm & \pm & \pm & \pm \\
\hline & & 0.2 & 0.4 & 0.01 & 0.01 & 0.2 & 0.5 & 0.3 & 0.8 & 0.2 & 0.02 & 0.3 & 0.6 & 0.4 & 0.2 & 0.2 & 0.2 \\
\hline PCF & S1 & 3.2 & 2.9 & 3.6 & 3.3 & 4.2 & 2.6 & 5.5 & 4.8 & 5.2 & 3.8 & 4.5 & 6.2 & 5.4 & 2.9 & 4.5 & 4.8 \\
\hline $\begin{array}{l}\text { position } \\
(\mathrm{mm})\end{array}$ & S2 & 4.9 & 2.6 & 6.2 & 4.5 & 5.2 & 4.8 & 3.9 & 4.6 & 6.2 & 4.8 & 4.2 & 2.9 & 3.9 & 2.8 & 3.8 & 5.5 \\
\hline MCF & S1 & 9.2 & 7.8 & 8.5 & 7.0 & 9.2 & 8.6 & 9.2 & 8.9 & 7.8 & 8.6 & 9.2 & 88.0 & 9.1 & 8.9 & 7.9 & 8.7 \\
\hline $\begin{array}{l}\text { position } \\
(\mathrm{mm})\end{array}$ & S2 & 3.8 & 4.5 & 4.7 & 3.9 & 4.8 & 5.3 & 4.6 & 3.9 & 7.6 & 4.6 & 5.3 & 4.6 & 4.2 & 5.4 & 5.0 & 4.9 \\
\hline Average & S1 & 3.10 & 3.50 & 4.50 & 4.19 & 2.92 & 3.80 & 4.20 & 2.92 & 4.2 & 5.20 & 4.8 & 3.97 & 2.18 & 4.77 & 5.12 & 6.12 \\
\hline $\begin{array}{l}\text { force of } \\
P C F(k N)\end{array}$ & S2 & 4.10 & 3.90 & 2.90 & 3.60 & 2.92 & 2.20 & 3.29 & 3.19 & 2.28 & 2.28 & 3.21 & 2.22 & 3.24 & 2.29 & 3.62 & 2.21 \\
\hline Average & S1 & 0.00 & 0.00 & 0.00 & 0.00 & 0.00 & 0.00 & 0.00 & 0.00 & 0.00 & 0.00 & 0.00 & 0.00 & 0.00 & 0.00 & 0.00 & 0.00 \\
\hline force of & S2 & 24.0 & 23.0 & 22.0 & 23.0 & 22.0 & 23.08 & 21.09 & 22.02 & 21.05 & 22.31 & 23.24 & 22.12 & 21.08 & 21.95 & 22.15 & 22.05 \\
\hline \multirow[t]{2}{*}{$\mathrm{MCF}(\mathrm{kN})$} & & $5 \pm$ & $4 \pm$ & $2 \pm$ & $5 \pm$ & $4 \pm$ & \pm & \pm & \pm & \pm & \pm & \pm & \pm & \pm & \pm & \pm & \pm \\
\hline & & 0.28 & 0.35 & 0.22 & 0.29 & 0.24 & $\overline{0} .28$ & $\overline{0} .31$ & 0.25 & $\overline{0} .4$ & $\overline{0} .22$ & $\overline{0} .24$ & $\overline{0} .39$ & $\overline{0} .32$ & $\overline{0} .48$ & 0.17 & 0.02 \\
\hline Weight & S1a & 1556 & 1548 & 1562 & 1550 & 156 & 1548. & 1552. & 1555. & 1565. & 1548. & 1539. & 1547. & 1552. & 1534. & 1548. & 1550. \\
\hline \multirow[t]{2}{*}{ variance } & nd & $.0 \pm 1$ & $.0 \pm 1$ & $.0 \pm 1$ & $.0 \pm 1$. & $0.0 \pm$ & $0 \pm 2.2$ & $0 \pm 1.8$ & $0 \pm 1.5$ & $0 \pm 1.4$ & $0 \pm 2.2$ & $0 \pm 2.5$ & $0 \pm 1.0$ & $0 \pm 2.2$ & $0 \pm 2.4$ & $0 \pm 1.8$ & $0 \pm 1.6$ \\
\hline & S2 & 20 & 50 & 28 & 35 & 1.42 & 0 & 0 & 0 & 2 & 4 & 0 & 5 & 0 & 0 & 9 & 7 \\
\hline Hardness & & $22 \pm$ & $22 \pm$ & $22 \pm$ & $22 \pm$ & $22 \pm$ & $22 \pm$ & $22 \pm$ & $22 \pm$ & $22 \pm$ & $22 \pm$ & $22 \pm$ & $22 \pm$ & $22 \pm$ & $22 \pm$ & $22 \pm$ & $22 \pm$ \\
\hline $\begin{array}{l}\text { range } \\
(\mathrm{kP})\end{array}$ & & 1.95 & 2.02 & 1.57 & 2.30 & 1.97 & 2.02 & 2.47 & 1.87 & 2.87 & 1.48 & 2.10 & 1.59 & 2.56 & 1.56 & 2.40 & 1.62 \\
\hline Thickness & & 7.98 & 8.00 & 8.00 & 8.10 & 7.95 & $8.05 \pm$ & $8.10 \pm$ & $8.05 \pm$ & $8.12 \pm$ & $8.01 \pm$ & $7.98 \pm$ & $8.05 \pm$ & $8.01 \pm$ & $8.12 \pm$ & $8.00 \pm$ & $8.12 \pm$ \\
\hline$(\mathrm{mm})$ & & $\begin{array}{l} \pm 0.1 \\
0\end{array}$ & 0.20 & $\begin{array}{l} \pm \\
0.20\end{array}$ & $\begin{array}{l} \pm \\
0.1\end{array}$ & \pm & 0.20 & 0.10 & 0.12 & 0.22 & $\begin{array}{l}0.0 .1 \\
2\end{array}$ & 0.01 & 0.21 & 0.2 & 0.14 & 0.2 & 0.1 \\
\hline $\begin{array}{l}\text { Disintegr } \\
\text { ation time } \\
\text { (min) }\end{array}$ & & 8 & 11 & 9 & 9 & 10 & 9 & 7 & 7 & 11 & 9 & 10 & 9 & 8 & 9 & 8 & 7 \\
\hline Friability & & $\begin{array}{l}0.1 \pm \\
0.01\end{array}$ & $\begin{array}{l}0.1 \pm \\
0.01\end{array}$ & $\begin{array}{l}0.1 \pm \\
0.01\end{array}$ & $\begin{array}{l}0.2 \pm \\
0.01\end{array}$ & $\begin{array}{l}0.2 \pm \\
0.01\end{array}$ & $\begin{array}{l}0.2 \pm 0 \\
.01\end{array}$ & $\begin{array}{l}0.2 \pm 0 \\
.01\end{array}$ & $\begin{array}{l}0.1 \pm 0 \\
.01\end{array}$ & $\begin{array}{l}0.2 \pm 0 \\
.01\end{array}$ & $\begin{array}{l}0.3 \pm 0 \\
.02\end{array}$ & $\begin{array}{l}0.2 \pm 0 \\
.02\end{array}$ & $\begin{array}{l}0.2 \pm 0 \\
.01\end{array}$ & $\begin{array}{l}0.3 \pm 0 \\
.01\end{array}$ & $\begin{array}{l}0.2 \pm 0 \\
.01\end{array}$ & $\begin{array}{l}0.1 \pm 0 \\
.02\end{array}$ & $\begin{array}{l}0.2 \pm 0 \\
.01\end{array}$ \\
\hline
\end{tabular}

${ }^{*} \mathrm{n}=3$, mean $\pm \mathrm{SD}$

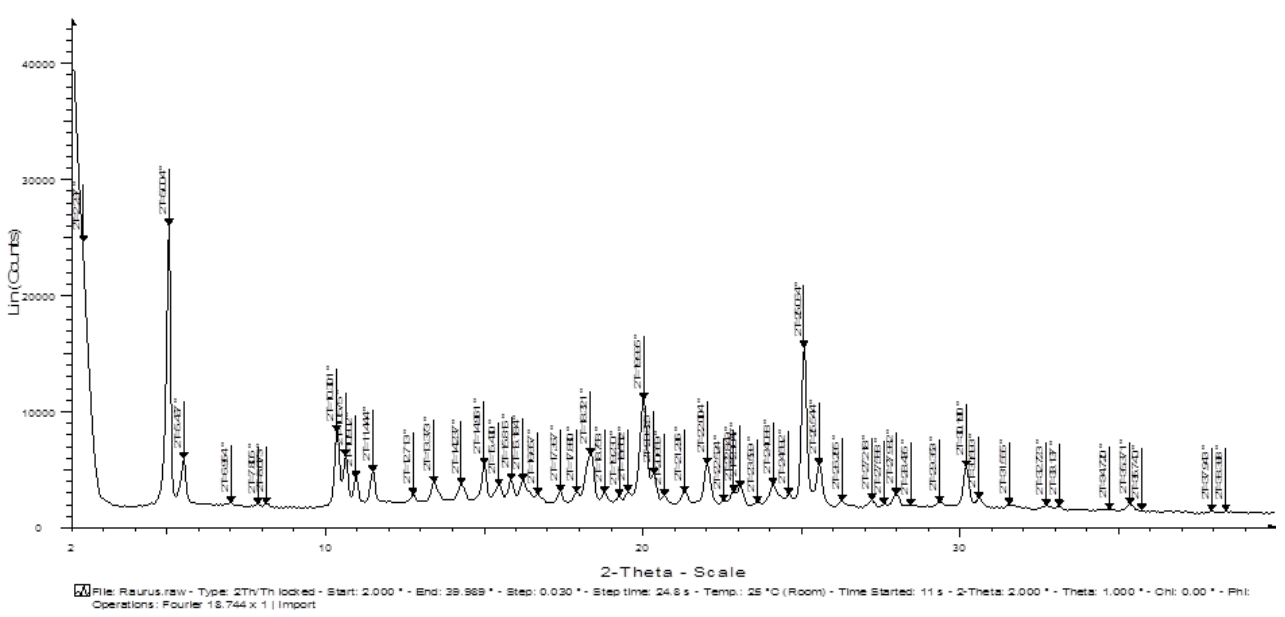

Fig. 5: The XRD profiles of tenofovir disoproxil fumarate (Form I) 


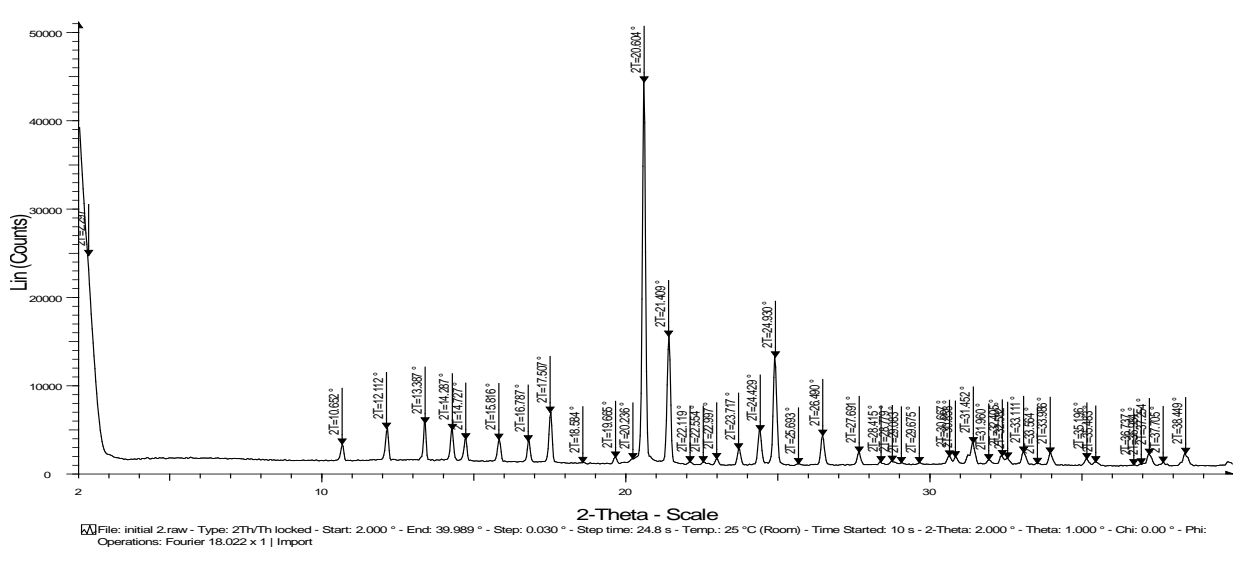

Fig. 6: The XRD profiles of lamivudine (Form I)

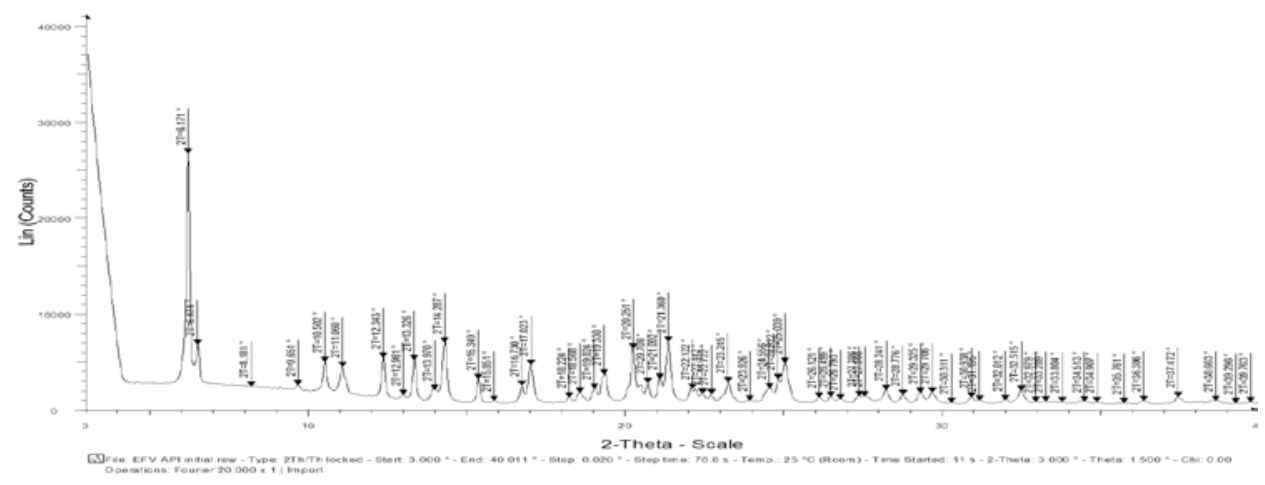

Fig. 7: The XRD profiles of efavirenz (Form I)

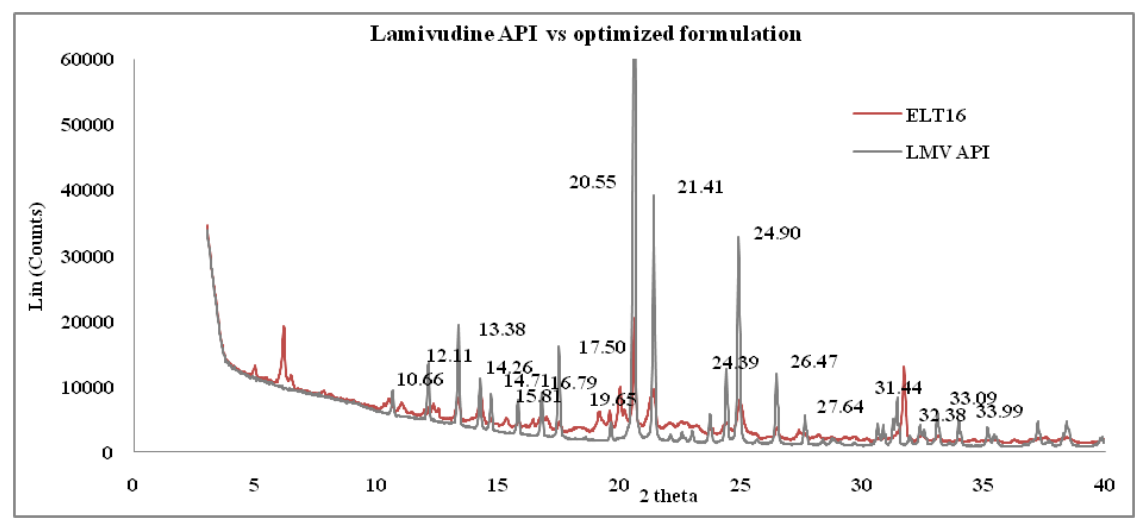

Fig. 8: XRD profile of active substance and finished product of optimized formulation (lamivudine)

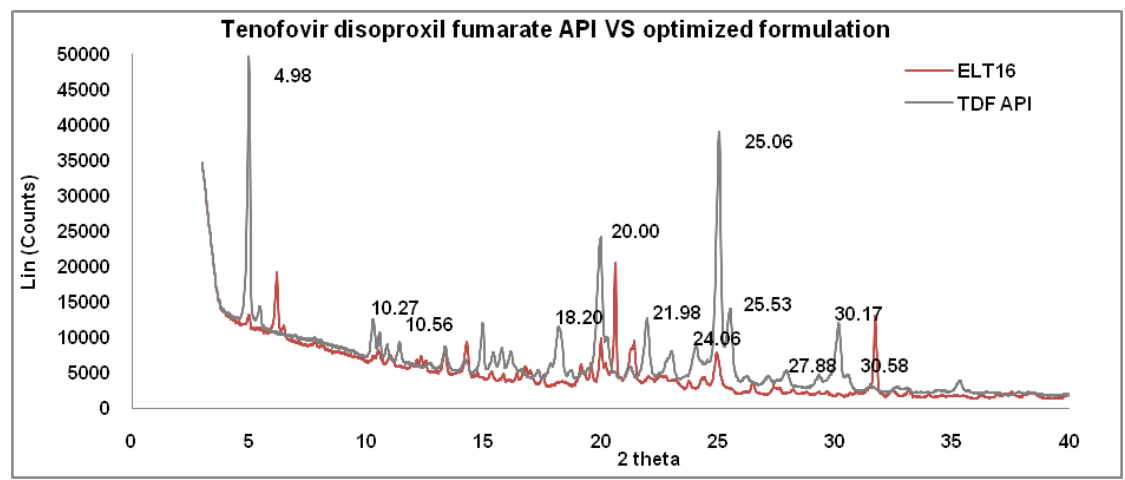

Fig. 9: XRD profile of active substance and finished product of optimized formulation (tenofovir disoproxil fumarate) 


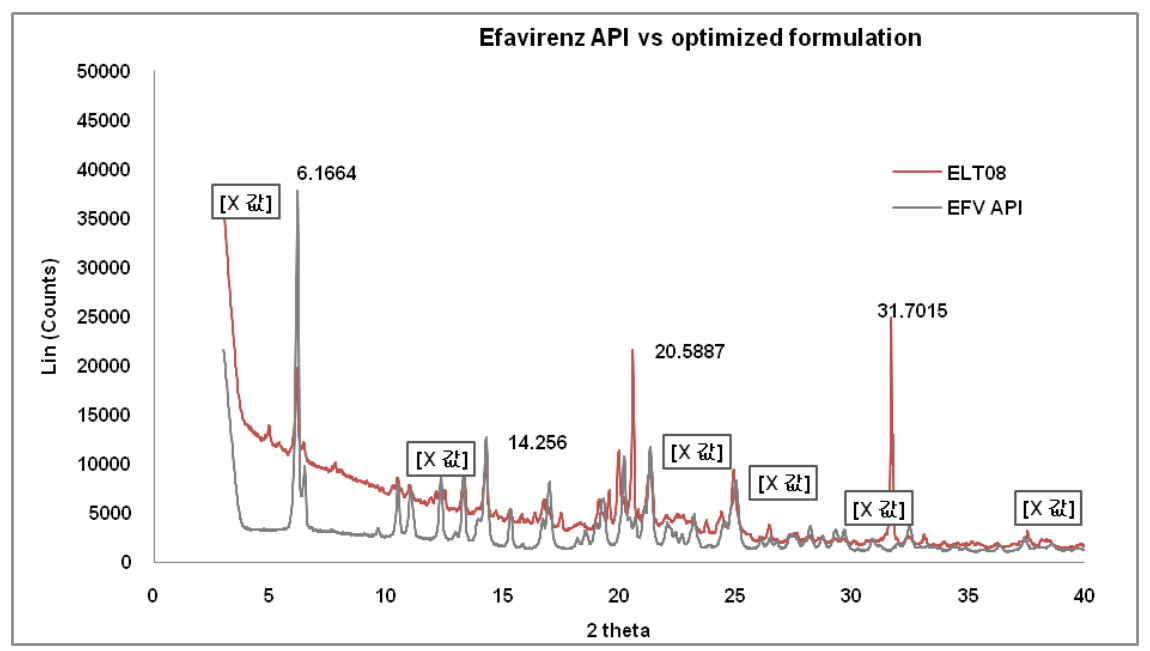

Fig. 10: XRD profile of active substance and finished product of optimized formulation (efavirenz)

\section{In vitro drug release studies}

Dissolution was carried out in purified water with $0.5 \%$ sodium lauryl sulfate (SLS), volume $900 \mathrm{ml}$, paddle speed 75 rotates per minute (RPM) for efavirenz and $0.1 \mathrm{~N}$ hydrochloride, volume: $900 \mathrm{ml}$, paddle speed, and apparatus: Type-II was used together for the lamivudine and tenofovir disoproxil fumarate. Coated tablets were used for the study of dissolution for the formulation study from ELT0 to ELT16. Further dissolution results for the optimum formulation compared with each innovator product. Results are presented in fig. 11-14 for reference.

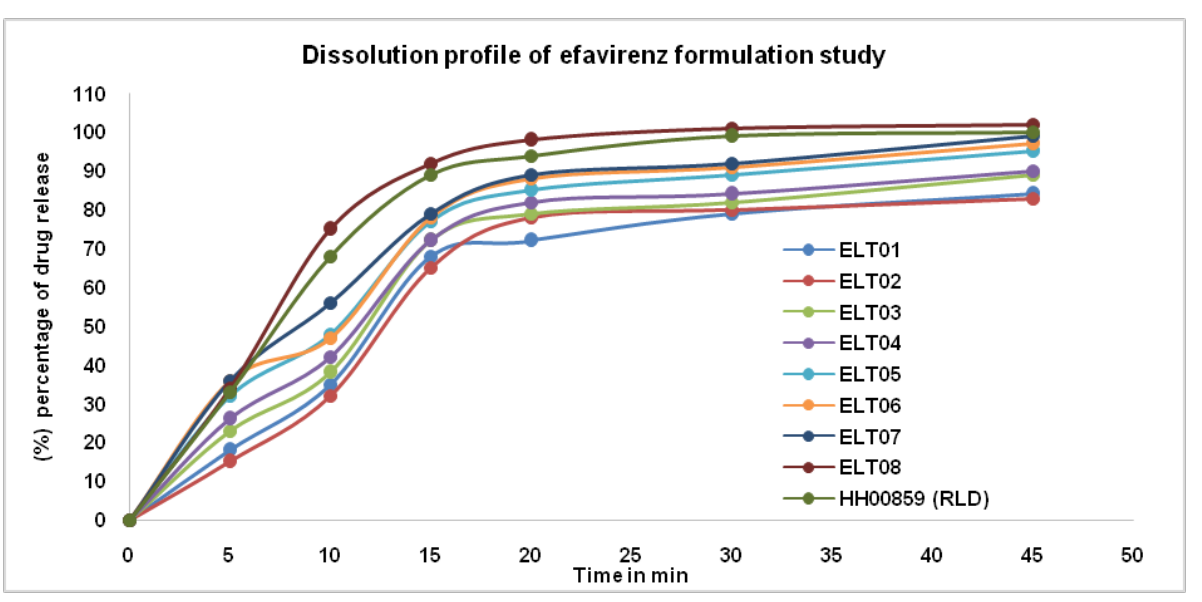

Fig. 11: Dissolution profile of efavirenz formulation study. The data is expressed as mean $\pm S D, n=3$

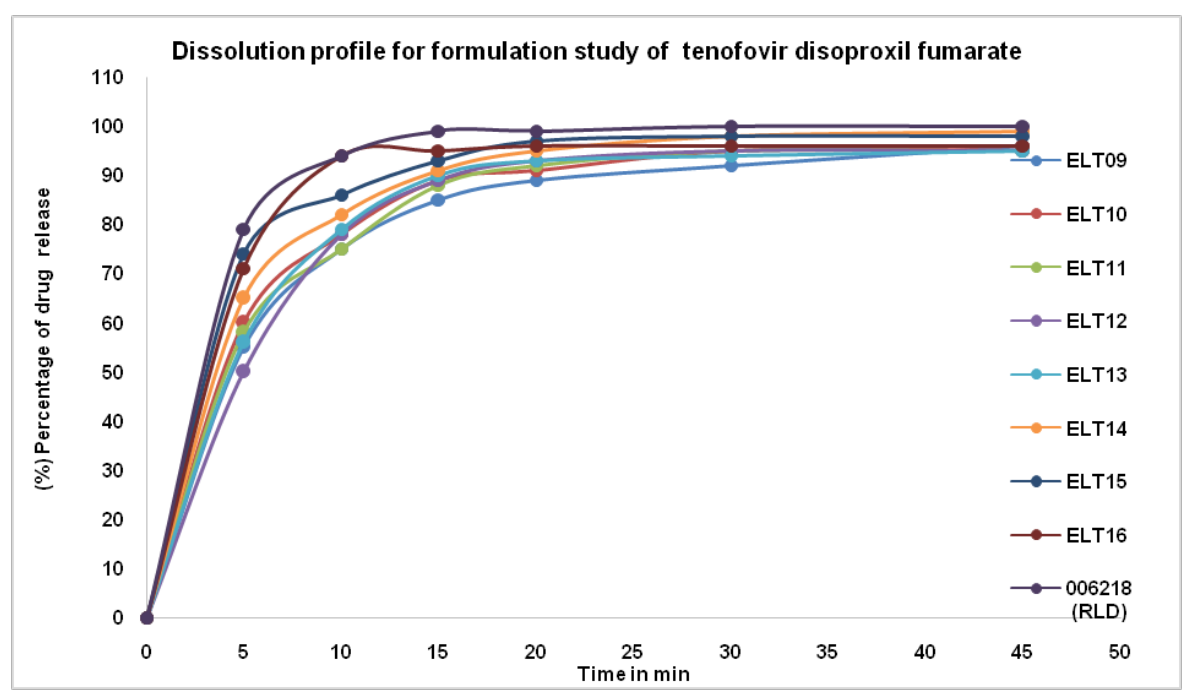

Fig. 12: Dissolution profile for formulation study of tenofovir disoproxil fumarate. The data is expressed as mean $\pm S D, n=3$ 


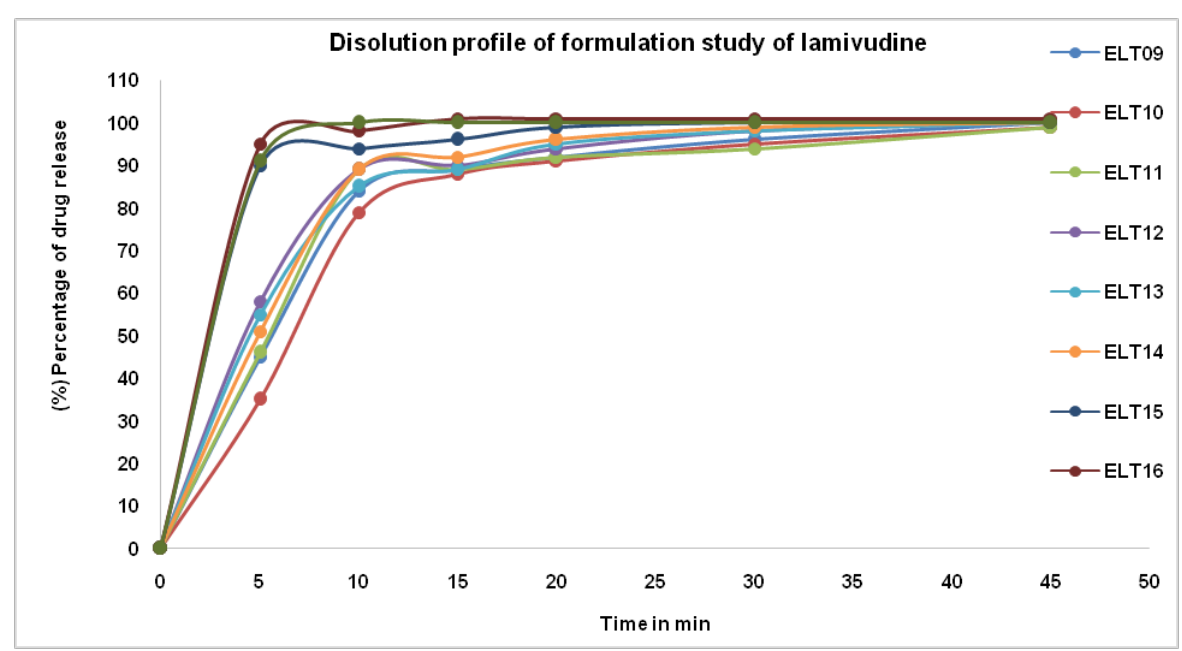

Fig. 13: Dissolution profile for formulation study of lamivudine. The data is expressed as mean $\pm S D, n=3$

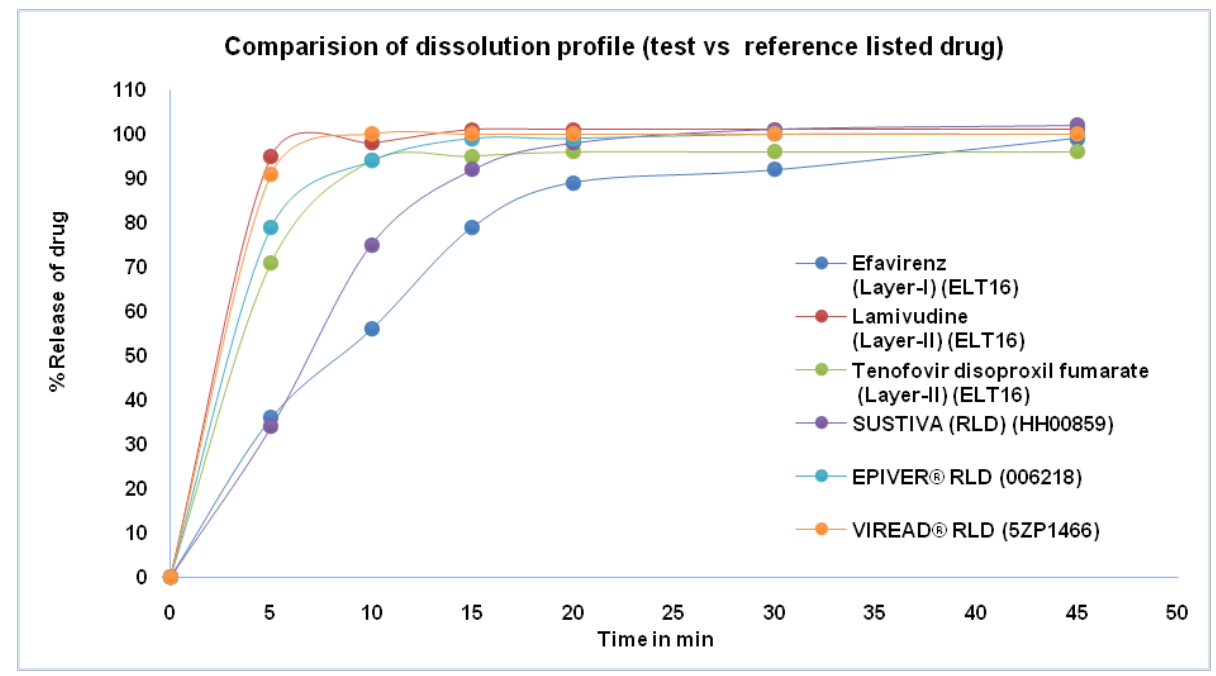

Fig. 14: Comparison of dissolution profile for test and reference drug product. The data is expressed as mean $\pm S D, n=3$

\section{DISCUSSION}

The formulation was designed by a preformulation study, which was suggested to understand the physical properties of the active substances and in-process blends to understand the flow properties. As per the Tibalinda, $p$ etel [8], pre-formulation data and previous experience, lamivudine and tenofovir part manufacturing was recommended to use direct blending followed by roller compaction process instead of the wet granulation process. Based on preformulation results also conclude that tenofovir is slightly sensitive to moisture and not suitable for the wet granulation process [10]. Drug-excipients results revealed that there was no interaction of active substances if the process was designed as bi-layer tablets [12]. Because of the poor flow properties of efavirenz, wet granulation process was recommended [13]. Further, excipients selection for both the layers of blends was selected as per the reference listed drugs [15-18]. In the case of efavirenz formulation, sodium lauryl sulfate is very critical and it acts as a wetting agent and increases the solubility of efavirenz, and directly influences the dissolution of drug product and this range was optimized [13]. Further, the croscarmellose sodium and microcrystalline cellulose range were optimized to improve the dispersion and enhance the disintegration of efavirenz in the formulation. Hydroxy propyl was added to the dry mix to ensure the proper binding with other excipients and to form good granules and this range was optimized. In the case of lamivudine and tenofovir formulation, microcrystalline and croscarmellose sodium has chances to affects the dissolution and friability of tenofovir. Powdered cellulose was acting as a diluent and flow property of the lamivudine part and it also affect the uniformity and dissolution of lamivudine. So, these ranges were optimized to ensure the uniformity and dissolution of tablets. Bilayer tablets were compressed with blends of the first layer is efavirenz followed by the second layer is Lamivudine and tenofovir through hardness range of $18-28 \mathrm{kp}$. Which have good compressibility and DT is comparable to the reference formulations $[9,13]$. In vitro dissolution media and conditions were selected based on solubility studies and other references [11, 13, 14, 20]. Finally, the optimized formulation of the dissolution profile was compared with each reference drug product and confirmed that the results were similar. Further, all the excipients quantities were used for the both layers of formulation followed to be within the inactive ingredients (IID) list as per the united states of food drug administration (USFDA) [18].

\section{CONCLUSION}

Fixed-dose formulations of efavirenz, lamivudine, and tenofovir disoproxil fumarate tablets $600 \mathrm{mg} / 300 \mathrm{mg} / 300 \mathrm{mg}$ was successfully manufactured with various percentages of surfactants, diluents, disintegrants, binders, and lubricants and finalized the stable formulation. Based on the solubility studies of three active substances, dissolution methods such as purified water with $1.0 \%$ sodium lauryl sulfate (SLS) for efavirenz and $0.1 \mathrm{~N}$ hydrochloric acid (HCL) for lamivudine and tenofovir disoproxil fumarate were 
selected. Based on drug-excipient studies, results confirmed that there is no interaction between both layers by using three active substances. Sodium lauryl sulfate is acting as a wetting agent and enhances the solubility of efavirenz and hydroxypropyl cellulose was added in the dry mix for uniform mixing with purified water as solvent in the wet granulation process and this range is critical for the dissolution. The roller compaction process and process parameters were designed to reduce the interaction of tenofovir and lamivudine along with magnesium stearate and improve the consistent uniformity and dissolution. X-ray diffraction (XRD) data also revealed that there was no change in polymorphism for the optimum formulation compared to active substances. It can be concluded that fixed-dose formulations are available as a single dosage regimen and show better in vitro drug release compared with innovator formulations.

\section{ACKNOWLEDGEMENT}

The authors are very much thankful to the management of remedium laboratories, hyderabad. for allowing utilizing the facilities for my research work.

\section{FUNDING}

Nil

\section{AUTHORS CONTRIBUTIONS}

All the authors contributed equally.

\section{CONFLICT OF INTERESTS}

The author declares that there are no conflicts of interest regarding the publication of the paper.

\section{REFERENCES}

1. Collier R. Reducing the pill burden. CMAJ. 2012;184(2):E117-8. doi: 10.1503/cmaj.109-4076, PMCID 3273525. PMID 22231682.

2. Joseph D, Thomas GM. A review on current applications of bilayer tablets. Res J Pharm Technol. 2019;12(5):2539-44. doi: 10.5958/0974-360X.2019.00427.X.

3. Devi KV, Pai RS. Antiretroviral: need for an effective drug delivery. Ind JP Sci. 2006. p. 1-6.

4. Witvrouw M, Van Maele B, Vercammen J, Hantson A, Engelborghs Y, De Clercq E, Pannecouque C, Debyser Z. Novel inhibitors of HIV-1 integration. Curr Drug Metab. 2004 Aug;5(4):291-304. doi: 10.2174/1389200043335487, PMID 15320701.
5. Chaudhary KPR, Devi A. International GS. J Res Pharm Sci. Manuscript No. IJRPC-254.

6. Flexner C. Antiretroviral agents and treatment of HIV infection. In: Brunton L, Chabner B, editors, Knollmann B. Goodman and Gilman's pharmacological basis of therapeutics. $12^{\text {th }}$ ed. New York: McGraw-Hill; 2011. p. 1623-64.

7. Martin A. Micromeretics. In: Martin à physical pharmacy. Baltimores. Lippincott Williams \& Wilkins; 2001. p. 423-54.

8. Tibalinda P, Pius D, Shedafa R, Masota N, Temu M, Kaale E. Preformulation development of lamivudine $300 \mathrm{mg}$ and tenofovir disoproxil fumarate (TDF) $300 \mathrm{mg}$ fixed dose combination tablets. PP. 2016;07(7):247-54. doi: 10.4236/pp.2016.77031.

9. Srilatha U, Ramakrishna M, Vasavi reddy D, Srinivas Reddy Devireddy. Formulation and evaluation of Emitricitabine and tenofovir disoproxil fumarate film coated tablets. Int J Res Pharm Sci. 2015:116-25.

10. Thota S, Radhalakshmi AK, Krishnanrajan D, Parthiban KG. Formulation and evaluation of immediate release tablets of lamivudine, zidovudine and nevirapine. Asian J Pharm Clin Res. 2009:54-61.

11. Panikumar AD, Venkatraju Y, Sunitha G, Sathesh babu PR, Subrahmanyam CVS et al. Development of biorelavent and discriminating method for dissolution of efavirenz and its formulations. Asian J Pharm Clin Res. 2012;5(3):220-3.

12. International Conference of Harmonization (ICH). Harmonized Tripartide guidelines for stability testing of new drug substances and products Q1A Convention, Inc. Vol. R2. Rockville, MD: United States Pharmacopoeial; 2003. p. 6.

13. Roy M, Ahmed I, Aziz I, Manju Pandy. Formulation and evaluation of efavirenz $600 \mathrm{mg}$ tablet. Mohd. Yaqub khan. Asian J Res Pharm Sci. 2015:153-67.

14. Prosper Tibalinda J Sempombe, Raphael Shedafa. Formulation development and optimization of lamivudine $300 \mathrm{mg}$ and tenofovir disoproxil fumarate $300 \mathrm{mg}$ FDC tablets by D-optimal mixture design; 2016. p. e00207. doi: 10.1016/j.heliyon,december2016,e00207.

15. https://extranet.who.int/pqweb/sites/default/files/HA593par t4v1.pdf [Last accessed on 10 Dec 2021]

16. https://www.medicines.org.uk/emc/product/9129/smpc\#gre f. [Last accessed on 10 Dec 2021]

17. https://www.accessdata.fda.gov/scripts/cder/iig/index.cfm. [Last accessed on 10 Dec 2021]

18. Handbook of pharmaceutical excipients Sheskey PJ, Hancock BC, Moss Gp, Goldfarb DJ, editors. 9th ed. 2020.

19. Cristoforetti R, Anita Nair, Bertil Abrahamsson. Biowaiver monographs for immediate release solid oral dosage forms: efavirenz. J Pharm Sci. 2013. doi: 10.1002/jps.23380. 